\title{
LA CUEVA DEL VALLE (ZALAMEA DE LA SERENA, BADAJOZ): UN SANTUARIO RUPESTRE EN LA COMARCA DE LA SERENA
}

\section{LA CUEVA DEL VALLE (ZALAMEA DE LA SERENA, BADAJOZ): A SANCTUARY CAVE IN THE REGION OF THE SERENA}

\author{
REBECA CAZORLA MARTÍN * \\ SEBASTIÁN CELESTINO PÉREZ *
}

Resumen: Se presenta un estudio preliminar sobre el santuario pacense de la Cueva del Valle a partir del análisis de los materiales arqueológicos documentados en el transcurso de sendas campañas de prospección desarrolladas en el lugar en los años 1999 y 2006.

Palabras clave: La Serena, santuarios, exvotos, romanización, paisaje sagrado.

\section{ANTECEDENTES}

El yacimiento de la Cueva del Valle, situado en el término municipal de Zalamea de la Serena (Badajoz) es conocido al menos desde comienzos del siglo pasado según las referencias de que disponemos ${ }^{1}$. Sin

* Instituto de Arqueología (CSIC, Junta Extremadura, Consorcio Mérida). El presente trabajo se enmarca dentro de los proyectos de investigación del IV Plan Nacional I+D+I del Ministerio de Ciencia e Innovación (2008-2011) HAR2009-10666 “Entre el Atlántico y el Mediterráneo: contraste de dinámicas en la evolución histórica del paisaje en el occidente peninsular a través de la Arqueología' así como del Plan Regional I+D+I de la Consejería de Infraestructuras y Desarrollo Tecnológico de la Junta de Extremadura PRI06B098 (2007-2009) "Sistemas de Información Geográfica aplicados a la investigación y planificación territorial del patrimonio arqueológico de la comarca de La Serena". Investigador principal: Sebastián Celestino Pérez.

1. Se trata de una carta, fechada en 1914 y conservada en la Real Academia de la Historia (CABA/9/7945/47(4) (Celestino Pérez y Celestino Pérez 2000: 54).
Summary: This paper shows a preliminary study on the Cueva del Valle sanctuary grounded in the analysis of the archaeological materials recovered during 1999 and 2006 survey campaigns developed in the site.

Key words: La Serena region, sanctuaries, exvotes, romanization, sacred landscape.

embargo, la primera publicación científica en el que aparece recogido es la memoria sobre la excavación arqueológica en el distylo romano de la propia Zalamea (García y Bellido y Menéndez Pidal 1963). Aproximadamente en esos mismos años tendrían lugar los primeros trabajos en la cueva que, en un primer momento durante la década de los 60 y comienzos de los 70, consistieron fundamentalmente en visitas de eruditos y aficionados, quienes recogieron abundante material cerámico y numerosos exvotos, así como en la organización de una "Misión Rescate" coordinada desde la escuela municipal de la localidad ${ }^{2}$.

Estas visitas y sobre todo la espectacular abundancia de materiales aportados por la cavidad motivaron

2. La realización de estas "Misiones de Rescate" fue un acontecimiento frecuente en la intrahistoria de muchos yacimientos peninsulares durante esas décadas. Un caso muy similar tuvo lugar en la Cueva Santa del Cabriel, una cueva-santuario conquense (Lorrio Alvarado et al. 2006: 49). 
el aviso al entonces Museo Arqueológico de Mérida, actual MNAR, y, como consecuencia, la autorización en 1977 de la primera excavación arqueológica propiamente dicha bajo la dirección de José $\mathrm{M}^{\mathrm{a}}$ Álvarez Martínez ${ }^{3}$. Sus resultados continúan inéditos si exceptuamos unas breve noticias incluidas en obras de conjunto sobre la Historia de Extremadura (Álvarez Martínez 1985; 1986), que han constituido hasta fechas recientes la única fuente de información bibliográfica sobre el yacimiento, citado desde entonces en numerosas ocasiones en publicaciones sobre la religiosidad y el poblamiento en la Extremadura prerromana (Berrocal-Rangel 1992; Enríquez Navascués 1995; Ortiz Romero y Rodríguez Díaz 1998) ${ }^{4}$. Una referencia importante, amén de temprana, la encontramos en la primera memoria de excavación de Cancho Roano, donde Maluquer de Motes describe el yacimiento al tiempo que señala ya la importante visibilidad de que dispone la pequeña cueva sobre la comarca de La Serena y la cuenca del río Ortigas (1981: 274). En ese mismo año, y también en un trabajo dedicado a Cancho Roano, Blanco Freijeiro menciona la Cueva del Valle, suscribiendo la consideración de García y Bellido, quien considera el lugar como un santuario indígena romanizado en el que se perpetuaría un determinado culto local al menos hasta época imperial. No menos importante es su referencia al conjunto de exvotos realizados en barro, tanto masculinos como femeninos, sumamente toscos, sin escuela alguna, como obras de alfareros más hechos a modelar cacharros que figuras humanas (Blanco Freijeiro 1981: 226), o la alusión a cuevas y promontorios como enclaves naturales que, bien por su especial configuración, bien por su significación en el paisaje, podían permitir al hombre sentir la presencia de la divinidad en ellos y, de este modo, sacralizarlos.

En todas estas referencias nada se nos dice sobre los posibles antecedentes u orígenes de este culto local, quedando igualmente incierta la divinidad (o divinidades) venerada en la pequeña cavidad. No obstante, sí encontramos algunas propuestas como la tradicional vinculación de cuevas y grutas con divinidades telúricas, infernales u oraculares, línea en la que han sido

3. Queremos agradecer en este punto a su excavador la colaboración prestada así como su disposición de cara a la futura publicación de una memoria sobre el yacimiento. Igualmente debemos agradecer la atención y facilidades brindadas por el Museo Arqueológico Provincial de Badajoz durante nuestros trabajos de revisión de los materiales arqueológicos procedentes de la intervención de 1977, realizados en el presente año.

4. En líneas generales todas estas citas bibliográficas destacan la importancia de la Cueva del Valle como uno de los escasos lugares de culto conocidos en el sector túrdulo de la Beturia en el que, a priori, se enmarcaría el yacimiento. interpretadas, por ejemplo, muchas de las cuevas-santuario levantinas 5 , o más concretamente, la propuesta de su excavador, quien considera el conjunto de exvotos como ofrendas realizadas por las poblaciones prerromanas a divinidades indígenas de las aguas (Álvarez Martínez 1986: 146).

Sobre los materiales cerámicos se ha señalado, en el monográfico que sobre la Beturia editase el Museo Nacional de Arte Romano en 1995, la personalidad de los mismos, ejemplo de cómo las poblaciones túrdulas serían el resultado de contactos e interrelaciones económicas, sociales y políticas con otros grupos, con enormes pervivencias y sincretismos (Enríquez Navascués 1995: 68). Respecto a los exvotos, se ha venido manteniendo la hipótesis planteada por Álvarez Martínez. En este sentido, Berrocal-Rangel (1992: 124) ha detectado un paralelo formal para los exvotos de la Cueva del Valle dentro del territorio extremeño en los hallazgos del Cerro de San Pedro (Valencia del Ventoso, Badajoz) y El Cantamento de la Pepina (Fregenal de la Sierra, Badajoz). Una referencia más reciente (Blech 2003) señala el carácter marcadamente indígena del conjunto frente a horizontes donde la romanización parece más profunda, caso del depósito votivo alto-imperial de Capote, a juzgar por el ofrecimiento de terracotas cuyos tipos remiten plenamente ya a la tradición romana ${ }^{6}$.

La primera publicación donde la Cueva del Valle deja de ser una breve referencia para adquirir mayor protagonismo es la que se elabora para el monográfico sobre santuarios y espacios sacros editado en 1997 por Quaderns de prehistòria i arqueologia de Castelló. En dicho trabajo, además de la descripción de la cueva en relación con el paisaje circundante, encontramos una primera publicación de sus materiales, en concreto una selección de exvotos antropomorfos así como de los vasitos cultuales, procedentes de una colección particular y recuperados durante la Misión Rescate a la que hacíamos referencia líneas atrás (Celestino Pérez 1997). En función de algunos de estos materiales se propuso entonces el comienzo de la actividad cultual en la cueva a finales del siglo $\mathrm{V}$ a.C. o más probablemente a comienzos del IV a.C., coincidiendo así con la destrucción ritual de Cancho Roano. Actualmente, nuestro estudio sobre los materiales procedentes de las prospecciones superficiales realizadas en 1999 y 2006,

5. Vid. González-Alcalde (2002). También González-Alcalde y Chapa (1993: 169-174).

6. Las terracotas de este Depósito están dentro de la tradición romana, según sus diferentes tipos, pero hechas con barro y moldes provinciales. El aspecto indigena, muy diferente, se refleja en las terracotas del santuario de Cueva del Valle, Zalamea de la Serena, en la misma provincia pacense (Blech 2003: 54). 


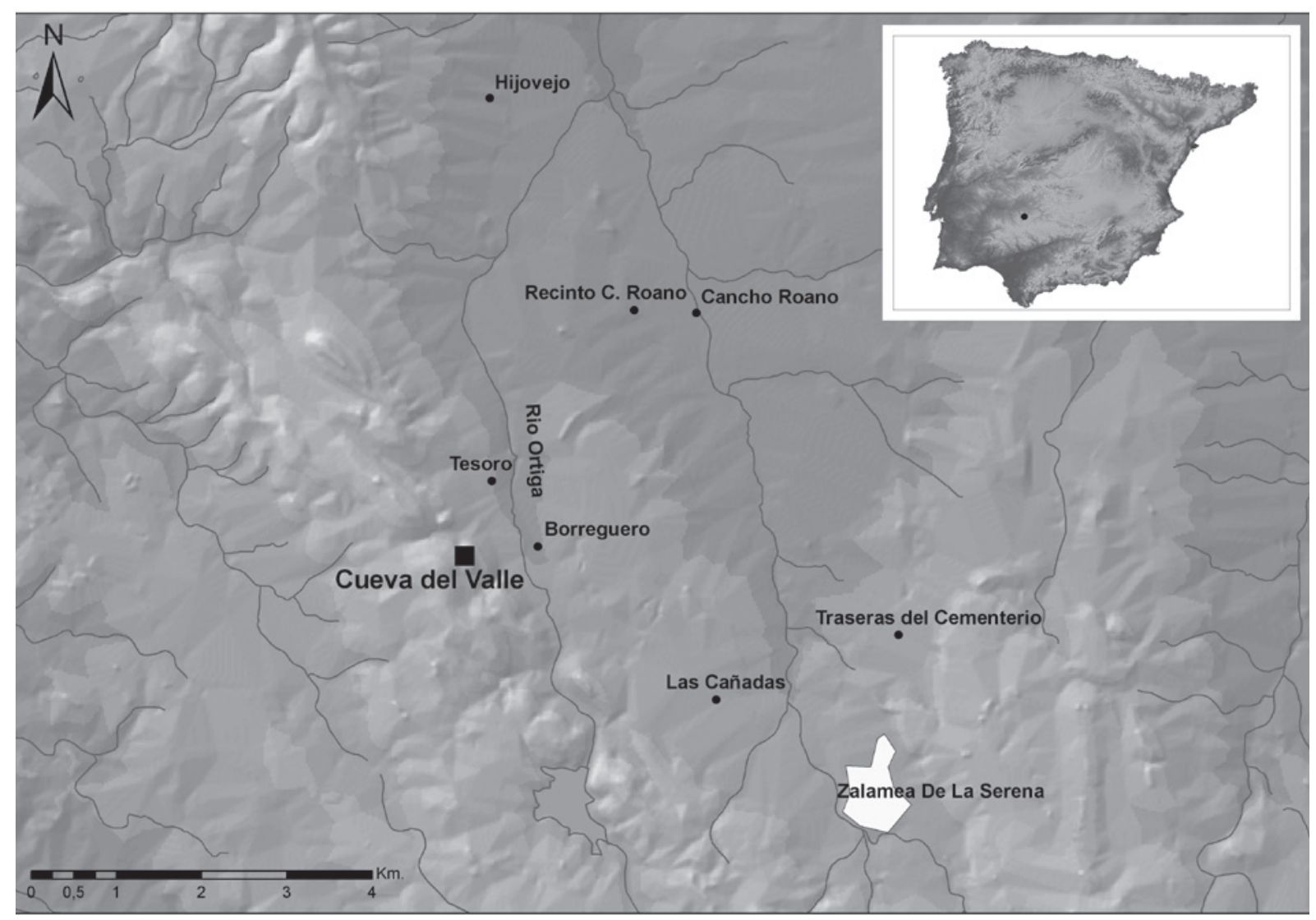

Figura 1. Localización del ámbito de estudio. Se indican los yacimientos arqueológicos mencionados en el texto.

únicamente nos permite documentar (y confirmar) una secuencia comprendida entre el siglo I a.C. y finales del I d.C., franja cronológica susceptible de ser ampliada conforme avance esta investigación.

Años después, en la tesis doctoral que sobre la religiosidad ibérica realizase Teresa Moneo, la Cueva del Valle aparece clasificada como un santuario de control territorial y no como una cueva-santuario, en función del pequeño tamaño del abrigo y de la presencia de exvotos de barro en su interior (2003: 83), características ambas que diferenciarían en su opinión esta cueva del conjunto de cuevas-santuario conocidas en el Levante peninsular. Respecto a la divinidad a la que presumiblemente se rendiría culto, la autora se desmarca de la hipótesis tradicional que vinculaba el sitio con una deidad de las aguas para proponer la existencia de una divinidad ibérica indígena de carácter celeste y solar, relacionada con los fenómenos atmosféricos y agrarios y asimilada después al Júpiter romano. No modifica en cambio la adscripción cronológica del sitio, que fecha desde finales del siglo V a.C. hasta el siglo II d.C.
Para finalizar este recorrido debemos hacer referencia a un trabajo de reciente publicación sobre la evolución del ritual religioso en el valle del Guadiana (Celestino Pérez y Tortosa 2008), donde se propone la consideración de este sector de La Serena como un paisaje sacro, a partir de la vinculación que existiría entre los yacimientos de Cancho Roano y la Cueva del Valle, definida como un abrigo-santuario. La conexión, tanto geográfica como visual, es evidente, circunstancia a la que habría que sumar la existencia de cursos de agua cerca de ambos o la presencia de vasos votivos en la cavidad que reproducen formas cerámicas antiguas ya documentadas en el palacio-santuario, aspecto sobre el que tendremos ocasión de volver más adelante.

Este último trabajo se enmarca, al igual que el que hoy presentamos, dentro de los proyectos de investigación que el Instituto de Arqueología viene desarrollando en los últimos años en la comarca de La Serena, Badajoz (vid. nota 1). Estos proyectos han constituido y constituyen un amplio marco donde tiene cabida la realización de campañas anuales de prospección 
intensiva ${ }^{7}$, intervenciones arqueológicas en algunos de los yacimientos más destacados, caso de los denominados recintos-torre localizados en torno al curso del Ortigas $^{8}$, o la revisión del santuario de la Cueva del Valle, investigación que desarrollamos actualmente atendiendo a varios puntos: de un lado, el estudio de los materiales recuperados durante las prospecciones superficiales realizadas durante 1999 y 2006, así como de aquellos procedentes de la intervención arqueológica dirigida por Álvarez Martínez en 1977. Todo ello se complementa con las excavaciones arqueológicas que nosotros mismos venimos efectuando en el sitio desde 2007 con objeto de comprender mejor el funcionamiento de este singular santuario y su papel dentro de la configuración y evolución del poblamiento de este sector de La Serena durante época protohistórica.

\section{EMPLAZAMIENTO Y DESCRIPCIÓN DEL YACIMIENTO}

El yacimiento de la Cueva del Valle o Cuevas de San José se encuentra situado en una pequeña cavidad abierta en un afloramiento natural de cuarcitas próximo a la cima del Cerro del Puerto (554 m), elevación que forma parte junto con el vecino Cerro del Docenario de la pequeña sierra que separa los términos municipales de Zalamea e Higuera de La Serena. Toda la zona se sitúa dentro de la Cuenca Hidrográfica del Guadiana, siendo sus recursos hídricos más importantes el río Ortigas, afluente del anterior, y el arroyo Cagancha, así como algunos arroyos tributarios de ambos. Tanto el Ortigas como el Cagancha presentan un curso generalizado de Sur a Norte, siendo el primero el curso de agua más próximo ya que discurre en la llanura situada a los pies de ambos cerros, apenas a 900 metros de distancia de la cavidad. Se da la circunstancia que este arroyo parece funcionar como un verdadero eje de articulación del poblamiento, al menos en lo que se refiere a la importante concentración de muchos de los denominados recintos-torre (de cronología tardorepublicana e imperial) en esta zona. Igualmente

7. En un primer momento estas campañas cubrieron el entorno inmediato de Cancho Roano: vid. Walid y Nuño, R. (2005: 977-984). Acerca de la campaña de 2007 en el valle del Ortigas vid. Mayoral, Cerrillo y Celestino (2009: 7-26.

8. En este sentido el Instituto de Arqueología viene realizando desde 2007 sondeos arqueológicos en algunos de estos recintos-torre como El Tesoro o Cerro Borreguero, ambos localizados en el término municipal de Zalamea de La Serena. Los resultados obtenidos serán objeto de una publicación en breve. es preciso reseñar la presencia junto al arroyo Cagancha del palacio-santuario de Cancho Roano, situado a unos $4 \mathrm{~km}$ de la cavidad (Celestino Pérez 1997; id. 2001).

Corresponde a este sector de la comarca de La Serena, integrado en el dominio del Complejo Esquisto Grauváquico dentro de la Zona Centro Ibérica (Quintana Frías y Boixereu Vila 2006), un relieve caracterizado por la presencia de grandes pliegues verticales con sinclinales paleozoicos que forman los relieves más altos y grandes extensiones deprimidas en los núcleos de los anticlinales pre-ordovícicos. Este relieve está fuertemente condicionado, como es lógico, por la litología: así, las zonas más deprimidas corresponden a los terrenos graníticos mientras que los relieves más acusados, como las sierras, coinciden con los afloramientos paleozoicos, fundamentalmente cuarcitas, como sucede en el Cerro del Puerto donde se sitúa la Cueva del Valle.

La comarca de La Serena ha constituido tradicionalmente un espacio de clara tradición ganadera, con amplias dehesas y pastos para una cabaña dominada por el ganado ovino. Dentro de esta comarca, configurada en conjunto como un espacio preciso y bien delimitado, es posible distinguir dos áreas diferenciadas en función de sus peculiaridades litológicas: el sector Este donde predominan los afloramientos cuarcíticos en torno al curso del río Guadámez, y el Oeste donde las pizarras enmarcan amplias dehesas de pasto.

La cavidad es, en realidad, un profundo abrigo con una amplia boca de $9 \mathrm{~m}$ de longitud orientada al Norte y ligera pendiente de excavación hacia el Sur. Su profundidad media $(8 \mathrm{~m})$ configura un área de $58 \mathrm{~m}^{2}$, quedando cegado el fondo por el derrumbe de varios bloques de cuarcita de gran tamaño, hoy además sumamente colmatado. No cabe duda de que estamos ante una cavidad natural formada en el afloramiento cuarcítico aunque resulta también evidente la presencia de distintas huellas de actuación antrópica tanto en las paredes laterales de la cavidad como en el techo de la misma, donde se aprecia un marcado rebaje respecto a la fractura natural de la cuarcita. Cabe suponer que sus dimensiones fuesen menores en origen, circunstancia que habría motivado, en un momento indeterminado, la ampliación de la superficie útil disponible. Igualmente se ha señalado la existencia de, al menos, una pequeña veta de prospección antrópica en busca de pequeñas mineralizaciones de hierro en el lateral derecho. Las posibilidades de explotación minera de este afloramiento consistirían básicamente en el aprovechamiento de pequeños enriquecimientos ricos en óxidos de hierro de carácter estratiforme (Granados 2007). En todo caso, parece evidente en función del citado rebaje la 


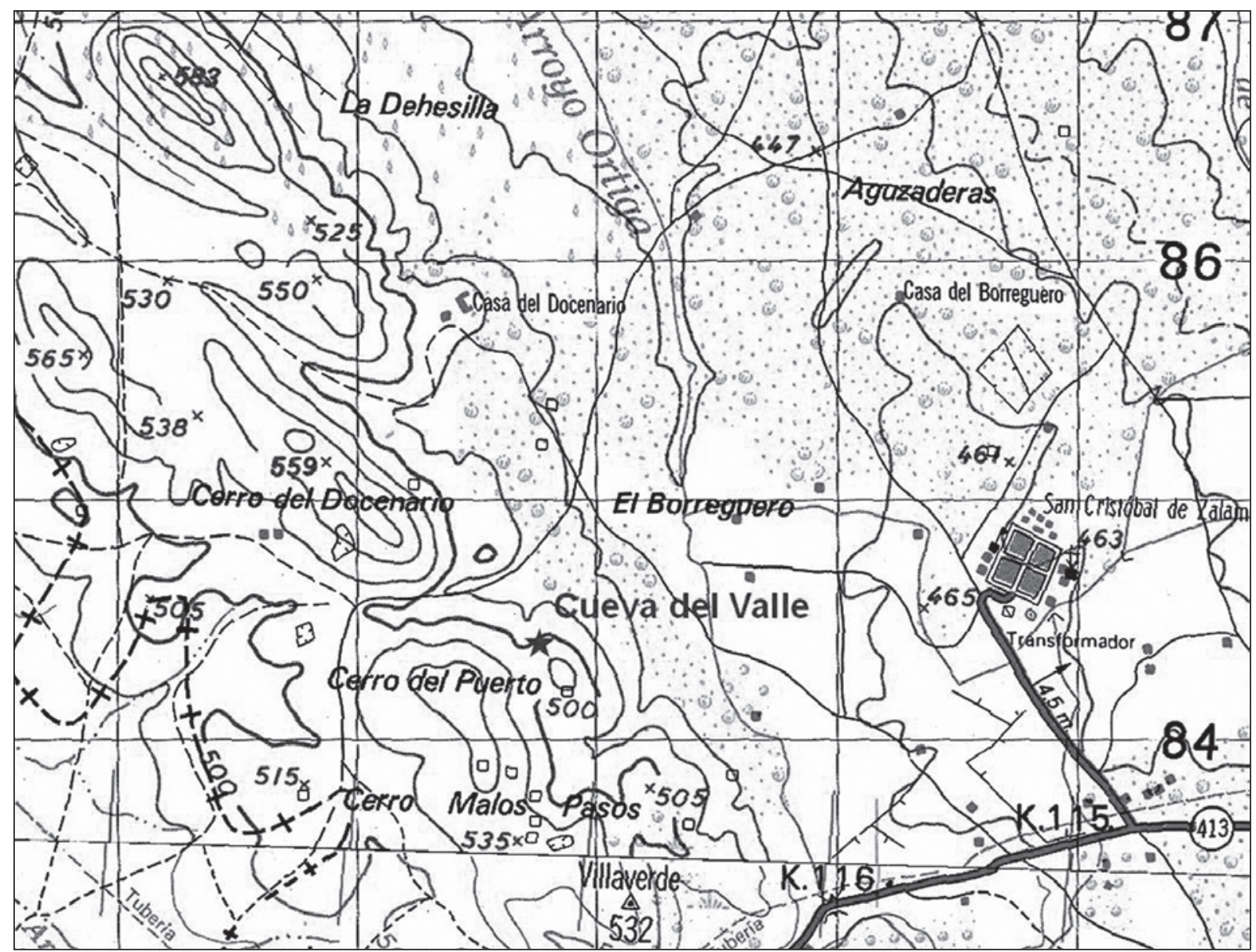

Figura 2. Mapa de situación del santuario. Hoja 805 MTN50 (detalle)

realización de una cierta adecuación de la cavidad natural, sin que podamos saber hoy por hoy si responde a esos posibles trabajos mineros previos o es consecuencia de la utilización del sitio como lugar de culto.

El yacimiento comprende otros espacios además de la cavidad propiamente dicha. Destaca en primer lugar la existencia de al menos tres escalones de acceso, retallados sobre los afloramientos naturales que facilitan el acceso a la boca de la misma desde el pequeño "pasillo" situado al Este. Es en este mismo pasillo donde se encuentra, perfectamente visible, una inscripción rupestre romana realizada en letra capital libraria donde puede leerse: “Q. CORNELIVS QVARTIO VI"9. La mayoría de especialistas han propuesto, en línea con Álvarez Martínez, su lectura como un voto a Júpiter realizado por Quinto Cornelio Quartio (Celestino Pérez 1997: 373), o bien como recoge el volumen

9. $\mathrm{CIL} \mathrm{II}^{2} / 7,923$.

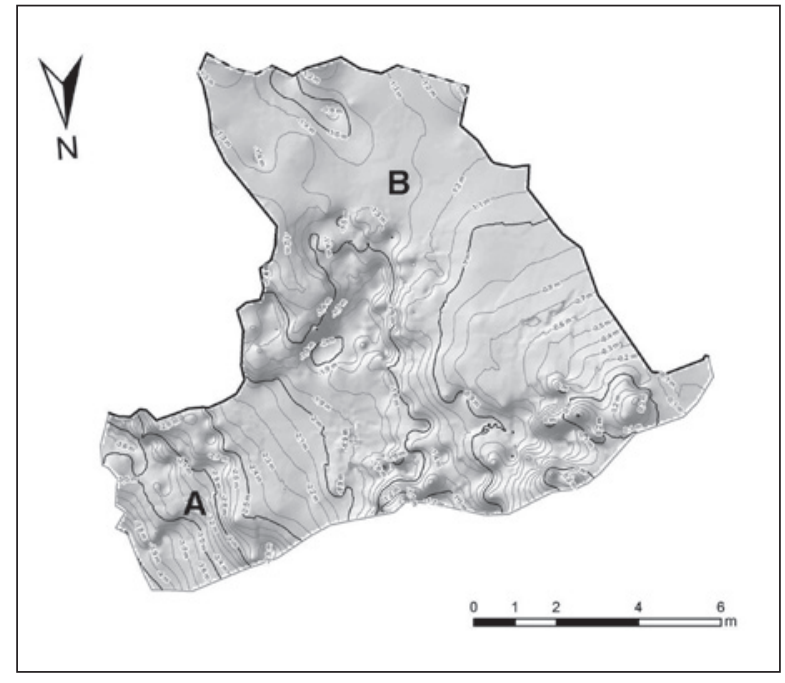

Figura 3. Planimetría y levantamiento topográfico de la Cueva del Valle. A: pasillo natural de acceso; B: interior de la cavidad. 


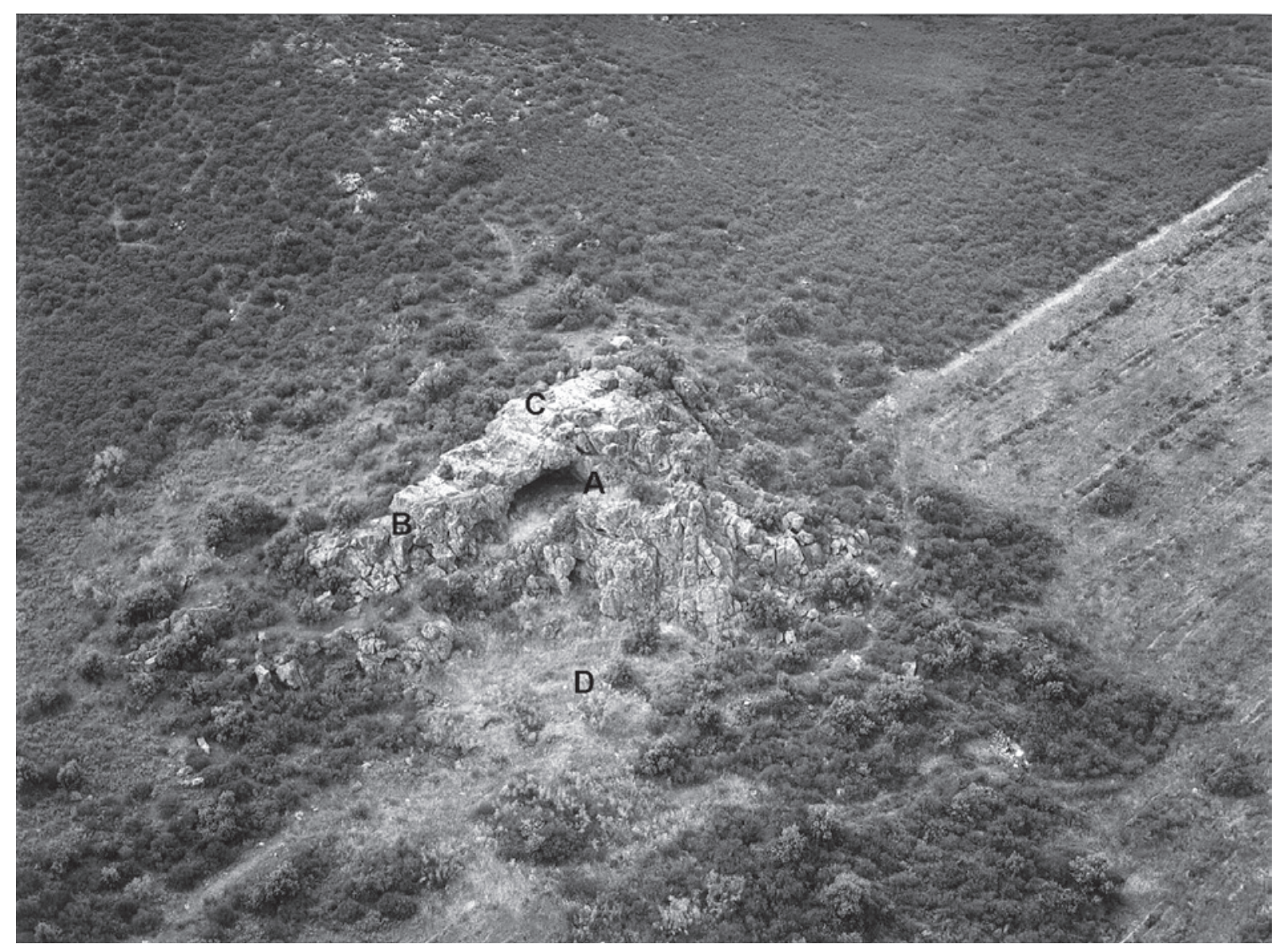

Figura 4. Vista aérea de la cavidad, con indicación de los distintos elementos del santuario: A: cavidad; B: localización de la inscripción rupestre; C: plataforma superior; D: terraza natural inferior. (Fotografía Sebastián Celestino).

del CIL dedicado al conventus cordubensis: Q(uintus) Cornelius Quart(---) Io/vi. La fecha propuesta para esta inscripción nos remite a la franja cronológica comprendida entre el 31-70 d.C.

Otros elementos significativos son, por un lado la gran explanada inferior que se abre inmediatamente bajo la boca de la misma, salvando el desnivel natural del afloramiento, explanada en la que se desarrolló la intervención de 1977 y donde nosotros mismos hemos planteado recientemente dos nuevos cortes cuyos resultados se encuentran en estudio. Por otro lado, en la parte superior de la cavidad encontramos una gran plataforma con huellas de extracción antrópicas, posiblemente derivadas del corte de bloques de cuarcita. Actualmente no tenemos elementos de juicio para determinar si esta plataforma natural fue desbastada con anterioridad para aprovechar la piedra o bien responde, como parece probable, a la adecuación de este espacio para la realización de determinados rituales de culto, posibilidad planteada en varias ocasiones (Maluquer de Motes 1981: 274; Celestino Pérez 1997: 373; Moneo 2003: 84).

En función de esta articulación espacial resulta evidente la existencia de ciertas similitudes con la configuración de algunos de los santuarios del Alto Guadalquivir: en Collado de los Jardines también encontramos un abrigo como lugar central del culto bajo el cual se erigió en época ibérica una plataforma artificial, mientras que en el santuario de Los Altos del Sotillo se ha podido documentar con claridad la existencia de un sistema formado por al menos cuatro terrazas que desde la cueva se abren hacia el Norte (Rueda Galán et al. 2008: 31-32). En el caso de la Cueva del Valle tanto la citada intervención de 1977 como los trabajos de prospección superficial realizados en 1999 y 2006 han demostrado, en virtud de los materiales localizados, la participación tanto del abrigo como de la gran explanada inferior en el desarrollo del culto. Estas similitudes serían 


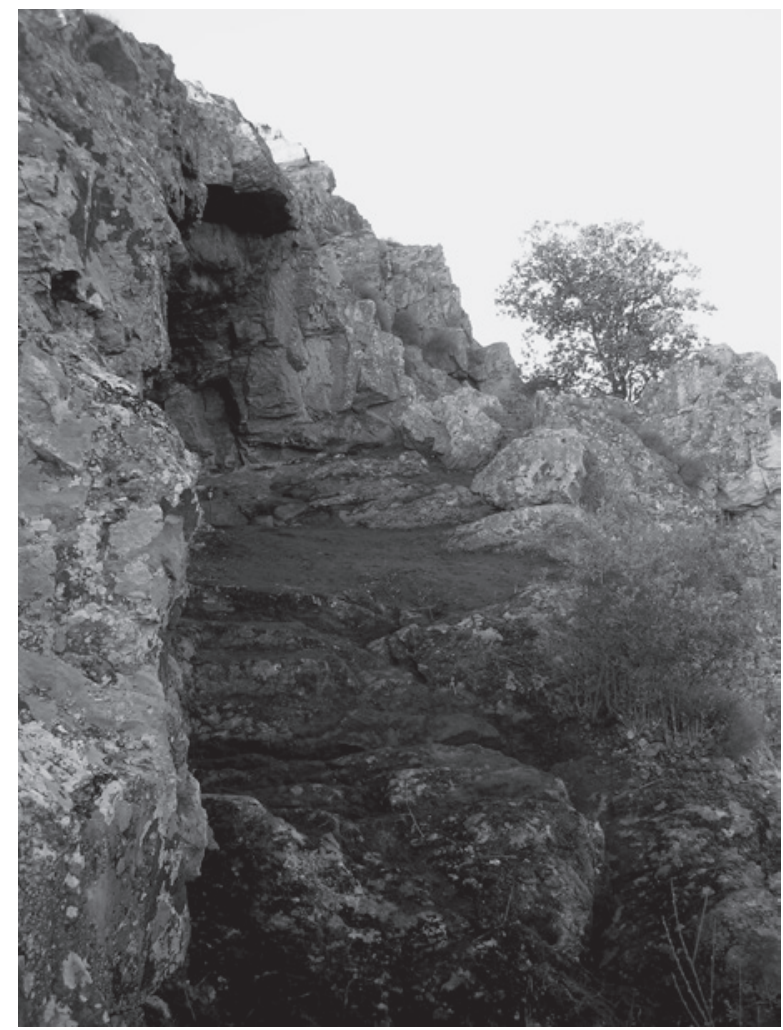

Figura 5. Vista del pasillo natural de acceso al interior de la cavidad desde la terraza inferior (fotografía Rebeca Cazorla).

aún mayores si consideramos la temprana romanización de que fueron objeto ambos santuarios jienenses o el hallazgo en ellos de varios exvotos ibéricos realizados en terracota, conjunto quizá menos conocido que la gran colección de exvotos de bronce pero que reviste un gran interés por cuanto puede ilustrar el proceso de transformación ideológica que supuso la romanización de estas poblaciones (Rueda Galán et al. 2008: 27). Sin embargo, en el santuario pacense no encontramos como en aquéllos terracotas romanas realizadas a molde, prueba de la plena aceptación final de los nuevos modelos iconográficos y que sí están bien presentes en cambio en contextos geográfica y cronológicamente próximos a la Cueva del Valle como el depósito alto-imperial de Capote (Berrocal-Rangel y Ruiz Triviño 2003).

Si analizamos la ubicación de este santuario en relación con el territorio en el que se inserta destaca en primer lugar la ausencia de evidencias sólidas que confirmen la existencia de poblamiento durante la Segunda Edad del Hierro en la zona. Los trabajos de prospección no han permitido hasta la fecha constatar la presencia

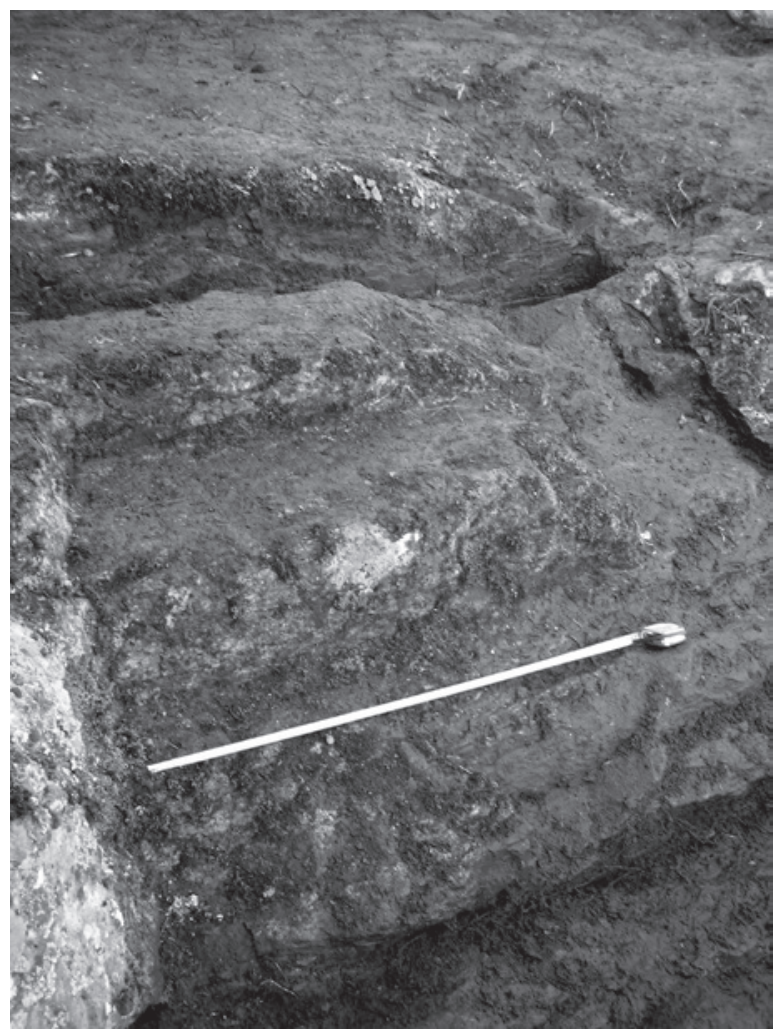

Figura 6. Escalones de acceso tallados en el afloramiento cuarcítico (fotografía Rebeca Cazorla).

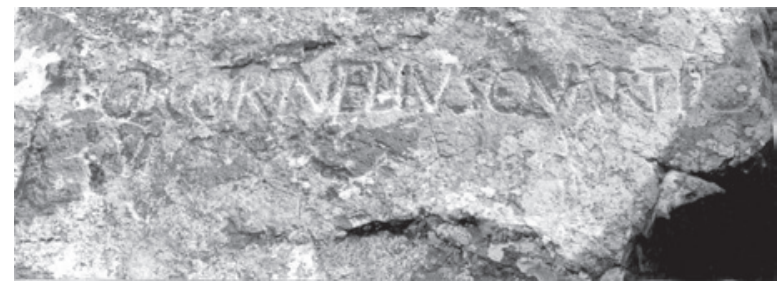

Figura 7. Inscripción rupestre (Fotografía CIL II²/7, 923).

de castros ni poblados adscribibles a dicha cronología al menos en lo que al entorno inmediato de la cavidad se refiere. Por el contrario, son bien conocidos estos niveles en asentamientos situados en un radio más amplio como Medellín, Magacela o la cercana localidad de Castuera (Rodríguez Díaz 1995: 105). La Carta Arqueológica de los términos municipales de Quintana y Zalamea de la Serena sí recoge algunos yacimientos fechados de forma genérica en la Segunda Edad del Hierro (tales como Cañabandera, Egido del Gravamen o Cancho Roano II entre otros), aunque debemos matizar 


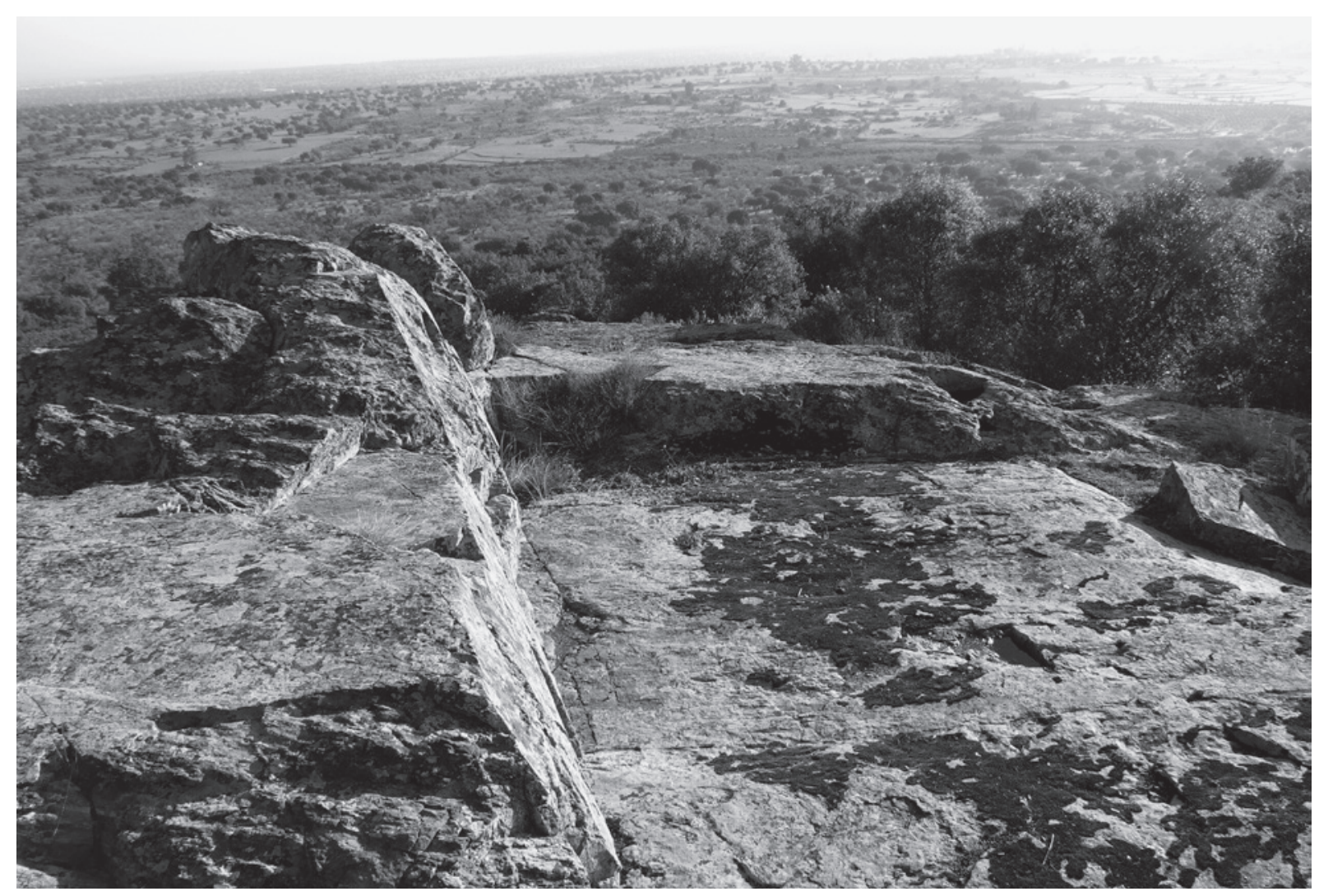

Figura 8. Plataforma tallada en la roca sobre la cavidad. Se aprecia el amplio dominio visual de que dispone el santuario (fotografía Rebeca Cazorla).

que la mayoría de ellos se corresponden con los citados recintos-torre, sin que se haya podido confirmar en ninguno de ellos la existencia de cronologías anteriores al siglo II a.C. Es el caso del recinto-torre de Hijovejo (Ortiz Romero 1991; Rodríguez Díaz y Ortiz Romero 2003), situado a 5,2 km de distancia de la Cueva del Valle y con el que parece compartir al menos parcialmente su cronología (siglo I a.C.- siglo I d.C.).

Es precisamente la presencia de muchas de estas singulares fortificaciones la que configura y caracteriza el poblamiento en torno al curso medio del Ortigas para época tardorepublicana e imperial. Tres de ellos se localizan en las inmediaciones de la cavidad dentro de un radio comprendido entre los 900, 1000 y $3000 \mathrm{~m}$ de distancia respectivamente: Cerro Borreguero ${ }^{10}, \mathrm{El}$ Tesoro y Recinto de Cancho Roano (vid. Fig.1). Estos asentamientos en llano se caracterizan por presentar un emplazamiento topográficamente poco prominente, a me-

10. En este caso, tanto las dimensiones como la propia configuración del sitio en su fase romana parecen diferenciarle de las características generales establecidas para los recintos tipo torre. nudo aprovechando afloramientos graníticos. Muestran plantas más o menos regulares (cuadrangulares o rectangulares) con uno o varios recintos concéntricos. En cuanto a la técnica constructiva suele ser constante la presencia de paramentos casi ciclópeos, construidos mediante grandes bloques de granito sin desbastar dispuestos en seco. Los materiales arqueológicos asociados a este tipo de yacimientos tienden a diferenciar dos fases sucesivas de ocupación, la primera de las cuales arrancaría a finales del siglo II a.C. o comienzos del siglo I a.C., siendo relacionada con el progresivo avance del control territorial romano en la zona. En un segundo momento, con cronologías ya claramente imperiales, se documentaría una reutilización de estos asentamientos integrados en una estructura de poblamiento rural.

Siguiendo con este recorrido, dentro también del término municipal de Zalamea de la Serena, encontramos otros enclaves parcialmente contemporáneos al santuario rupestre, aunque localizados a una distancia mayor, en un radio comprendido entre los 3,5 y los $5 \mathrm{~km}$ Es el caso de las villae romanas de las Traseras del Cementerio y Las Cañadas (Fig.1), conocidas 
únicamente por trabajos de prospección. Los materiales localizados en superficie permiten proponer una cronología del siglo I d.C. para ambas.

Mención aparte, tanto por su singularidad como por su cronología merece la presencia del palacio-santuario de Cancho Roano, a cuya bibliografía específica remitimos. Ya hemos aludido anteriormente a la sugerente posibilidad de que exista una cierta continuación o quizá traslado del culto a la cavidad tras la destrucción ritual de aquél a finales del siglo V a.C. (Celestino Pérez 1997 ${ }^{11}$. Ciertas evidencias, como la presencia entre los vasitos votivos de formas cerámicas presentes en el palacio-santuario (caso de las ánforas tipo CR-1), avalan la existencia de una cierta conexión entre ambos y permiten plantear esta hipótesis. Sin embargo, el estudio de los materiales procedentes de la prospección superficial del yacimiento no nos permite hasta la fecha contrastar esta propuesta, siendo significativa la ausencia de materiales diagnósticos que nos permitan cubrir este hiato cronológico. La escasa información que a este respecto aporta el grueso de materiales cerámicos documentados contrasta con la presencia de un notable conjunto de producciones romanas que atestiguan la perduración del culto en este lugar durante el siglo I d.C., quedando más difusos sus orígenes. En todo caso, resulta igualmente sugerente la presencia de dos santuarios tan diferentes dentro de un mismo paisaje y en un radio tan reducido, permitiendo proponer la consideración de este entorno como un verdadero espacio sagrado.

\section{LOS MATERIALES ARQUEOLÓGICOS}

La extraordinaria abundancia de material cerámico recuperado durante los trabajos de prospección superficial hizo necesaria y aconsejable a la hora de abordar su estudio proceder a una primera separación y clasificación del mismo. De este modo, presentaremos por un lado únicamente las formas realizadas en cerámica común y, por otro, aquellos materiales que podríamos considerar "selectos" en función de su significación cronológica y/o cultual. Dentro de este segundo grupo se encuadran también todas las producciones romanas documentadas en el yacimiento: paredes finas, TSH precoz o sigillatas de imitación tipo Peñaflor, terra sigillata o lucernas. Por último dedicamos un apartado a

11. En todo caso estaríamos ante rituales de claramente diferenciados: el banquete colectivo y la ofrenda de productos suntuarios en el palacio-santuario frente a una comunicación más individual y privada con la divinidad en la Cueva del Valle (Celestino Pérez y Tortosa 2008: 483). los materiales propiamente votivos, caso de los vasitos cerámicos en miniatura y los exvotos antropomorfos.

\subsection{Cerámica común}

La cerámica común de almacenamiento y cocina constituye sin duda el grupo más numeroso documentado; así, sólo la campaña desarrollada en 1999 aportó un total de 459 fragmentos de formas cerámicas de los cuales 337 corresponden a bordes, 102 a bases y 20 son asas. Son siempre cerámicas realizadas a torno, con superficies alisadas de forma somera por lo general, y donde las pastas se caracterizan por presentar desgrasantes de cuarzo de grosor muy fino a fino; en cuanto a la cocción de los recipientes es preciso señalar el marcado predominio de los ambientes oxidantes frente a los reductores (81,91\% de los primeros por el 9,58\% de los segundos).

Cabe resaltar dentro de este conjunto de cerámicas comunes la existencia de una serie de fragmentos (39) bien diferenciado que hemos definido como comunes de pasta clara, caracterizadas por un acabado mucho más cuidado, con superficies alisadas, pastas finas y bien depuradas, de núcleo reductor grisáceo y superficies de color blanquecino-amarillento, fruto quizás de la aplicación de caolín a la arcilla o bien resultado de una sobrecocción. Estas producciones representan el 8,51\% del total de fragmentos recuperados. Es sobre este tipo de cerámicas donde documentamos decoraciones pintadas, consistentes en una o dos bandas horizontales de color rojo vinoso o castaño.

En cuanto a las formas detectadas, un tipo sobresale por su excepcional abundancia y regularidad morfológica: las páteras o platos de borde simple reentrante y pie anular, siempre con cocciones oxidantes y cuyo diámetro medio oscila generalmente entre los 14 y los 19 centímetros. En segundo lugar encontramos una forma bastante similar, como son pequeños cuencos con borde sin diferenciar o escudillas, con paredes ligeramente convexas, de nuevo siempre cocidos en ambientes oxidantes. Buena prueba de su abundancia es el importante porcentaje $(36,38 \%)$ que representan dentro del total los bordes adscribibles a estas formas cerámicas. Se trata en ambos casos de formas propias de una vajilla de mesa, aptas para contener, servir y/o consumir alimentos tanto líquidos como sólidos. Presentan además una amplia difusión cronológica, siendo bien conocidas tanto en las tipologías de la cerámica ibérica (como ejemplo, subtipos 8.2 y 8.3 de Mata y Bonet) ${ }^{12}$ como de la cerámica común romana (tipos 20 y 21 de

12. Mata y Bonet (1992: 17-174). 

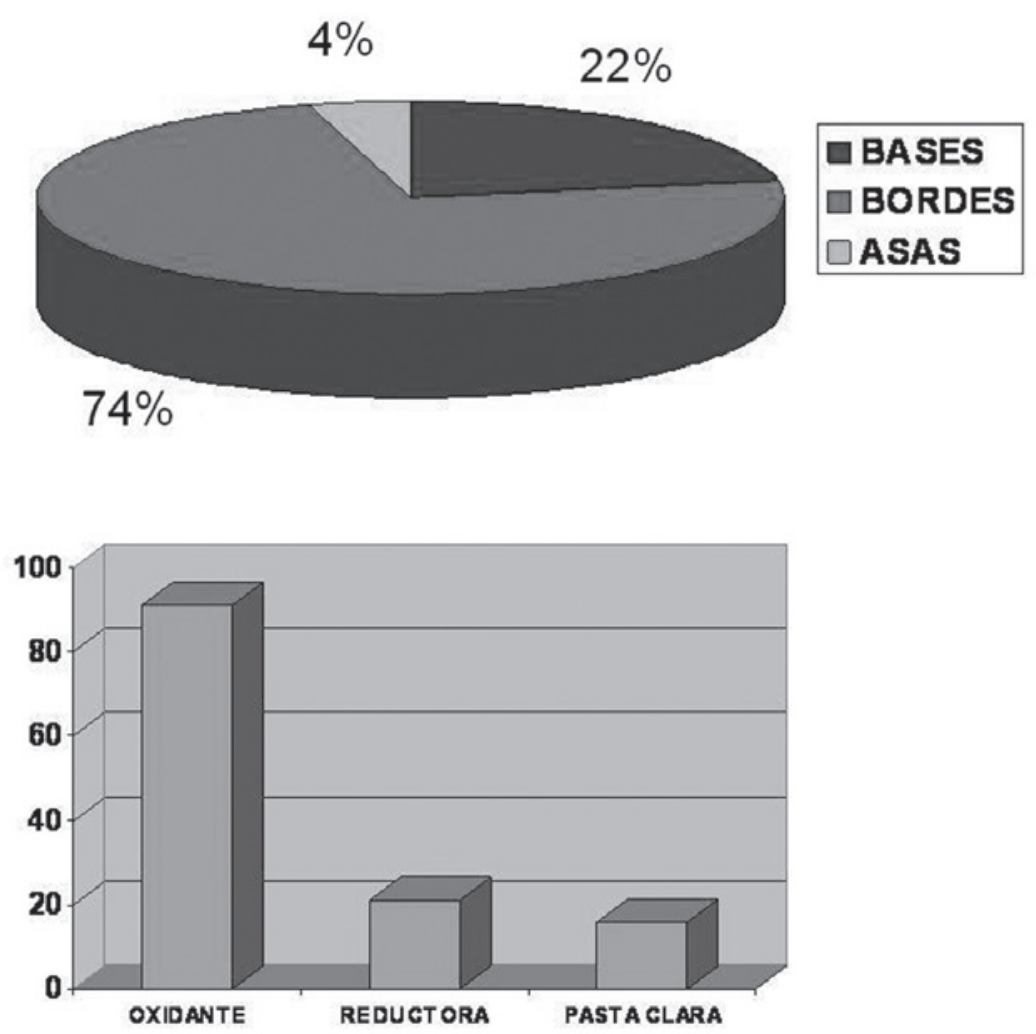

Figura 9. Cerámica común (campaña de prospección de 1999): porcentajes de aparición por forma y tipos de producción.

Vegas). En nuestro caso, dada la ausencia de decoraciones así como la escasa significación de sus pastas no podemos extraer de las mismas indicación cronológica alguna, debiendo recurrir para ello a otro tipo de materiales, caso de las producciones netamente romanas.

Junto a páteras y escudillas encontramos otro tipo de formas, también características de la cerámica común, en este caso de cocina, como son las ollas y cazuelas de borde exvasado, cuello corto y cuerpo globular. Otros fragmentos muestran ciertas variantes como el borde escalonado. En unas y otras advertimos de nuevo una preferencia por las cocciones oxidantes, aunque también aparecen fragmentos con cocción reductora.

La presencia de cerámica común en este tipo de yacimientos está demostrando ser más frecuente de lo que los primeros trabajos sobre cuevas y abrigos santuario parecían indicar. En este sentido cabe citar la Cova dels Pilars, en Alicante, que ha proporcionado un numeroso conjunto de materiales entre los que se encuentra casi un centenar de ollas de cerámica ibérica de cocina para las que se ha propuesto su interpretación como contenedores de ofrendas y no como ofrendas en sí mismas dado que el valor de este tipo de recipientes no parece superar el meramente funcional (Grau 2000: 365). Una treintena de ollas de cocina de perfiles y tamaños muy similares a éstas aparecieron en otra cueva santuario alicantina, la Cova de La Moneda. Recipientes de cerámica común a torno encontramos también en el santuario ibérico de Cueva Merinel, aunque en menor número (Martínez Perona 1992: 270). También en las Cuevas del Puntal del Horno Ciego se han documentado varios ejemplares de ollas de cocina, interpretadas igualmente como posibles contenedores de algún tipo de ofrenda (Martí Bonafé 1990: 148-149). En todos estos casos tanto las cronologías propuestas (siglo V a.C. a mediados del IV a.C.) como los ámbitos geográficos y culturales se alejan evidentemente de nuestro caso de estudio, pero consideramos oportuno incluir estas referencias por cuanto ilustran bien el progresivo avance en la investigación y conocimiento de estos santuarios 


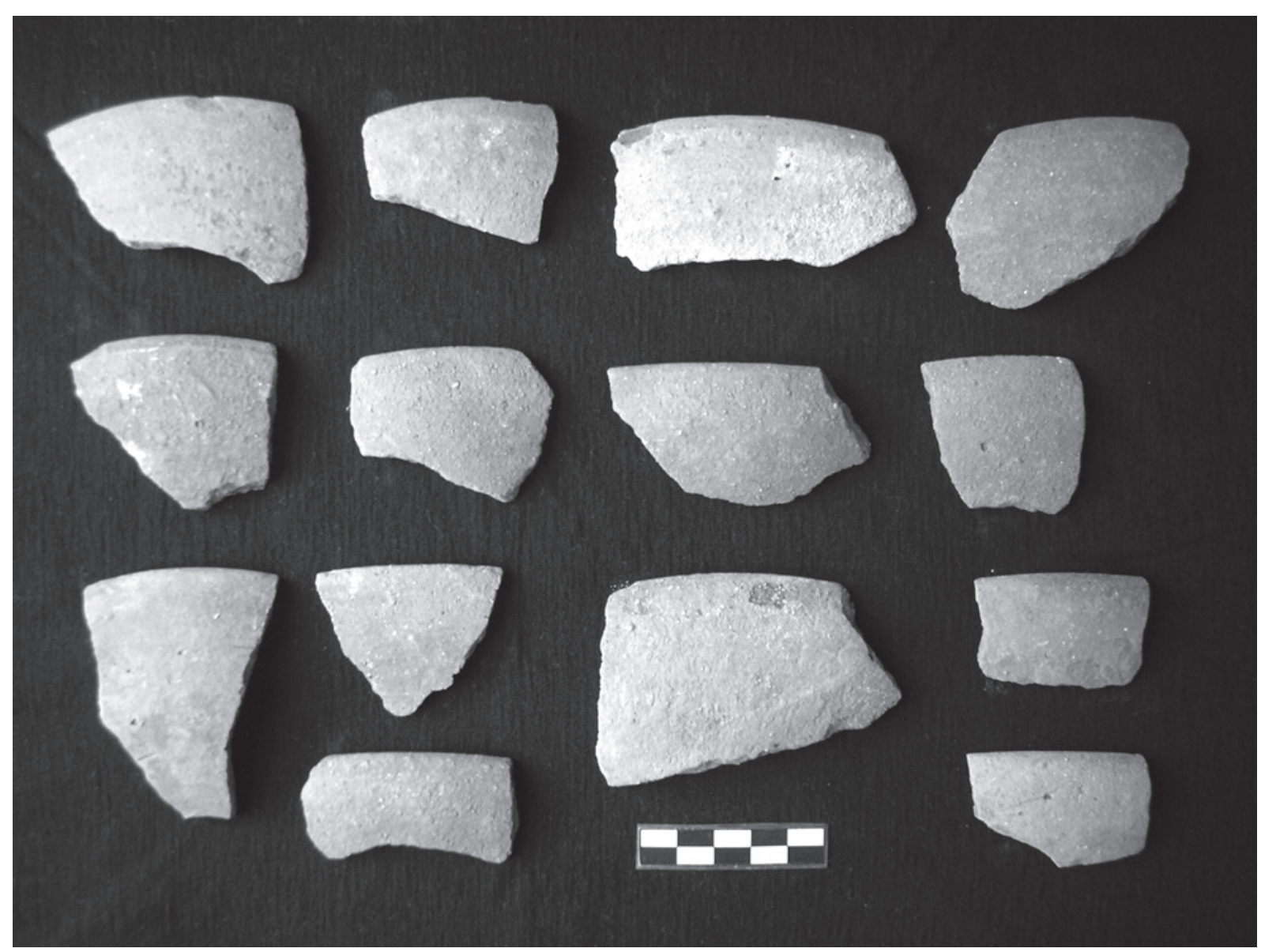

Figura 10. Bordes de pátera realizados a torno (selección). Prospección arqueológica de 1999 (fotografía Rebeca Cazorla)

rupestres. Dicho avance se viene traduciendo en una ampliación del mapa de dispersión peninsular de las cuevas y abrigos santuario, del abanico cronológico que pueden presentar, en ocasiones con sucesivas y prolongadas ocupaciones que se adentran incluso en época imperial, o del registro material asociado, bastante más variado de lo contemplado inicialmente.

Dentro de la cerámica común recuperada encontramos dos tipos de decoraciones bien diferenciadas: a los recipientes de cocina oxidantes realizados a torno, ollas fundamentalmente, corresponden cuatro fragmentos de galbos, así como un borde exvasado, que presentan una sencilla decoración de cordones aplicados formando ondas con amplias digitaciones en los mismos; en cambio, entre las producciones de mayor calidad, o de pasta clara, a las que hemos aludido antes la decoración consiste en la presencia de sencillas bandas horizontales de pintura en tonos rojo vinoso, anaranjado o castaño aplicadas en el exterior de la pieza, bien sobre el cuerpo del recipiente (cuatro fragmentos de galbos) bien delineando el borde (tres fragmentos de bordes simples engrosados al exterior y ligeramente exvasados). Cabe destacar la total ausencia de cualquier tipo de decoración, según la información de que disponemos hasta el momento, tanto en páteras como en escudillas, formas más frecuentes dentro del repertorio de cerámica común documentado.

Por último, dentro también de la cerámica común, debemos mencionar el singular hallazgo de tres bases de recipientes recortadas intencionalmente; este curioso procedimiento no parece ser exclusivo de una forma o una factura específicas por cuanto lo encontramos tanto sobre pies anulares con umbo central (en cocción oxidante la primera y reductora la segunda) como sobre una pequeña base plana, de $5 \mathrm{~cm}$ de diámetro, de pasta bien depurada y tonos grisáceos. En la bibliografía consultada al efecto hemos podido encontrar un único paralelo que nos remite de nuevo a las Cuevas del Puntal del Horno Ciego (Villargordo del Cabriel, Valencia), donde se documentaron dos bases anilladas 
de pasta gris recortadas (Martí Bonafé 1990: 157; piezas $n^{\circ} 7062$ y 7096), interpretadas como deposiciones de ofrenda, posibilidad que no debemos descartar para la Cueva del Valle.

\subsection{Producciones romanas}

Frente a la cierta indefinición cronológica que muestra la cerámica común, el hallazgo de un importante conjunto de producciones netamente romanas puede orientarnos en ese sentido, así como señalarnos posibles zonas de procedencia $y$, por extensión, rutas comerciales en este sector de la Beturia túrdula. Dentro de las producciones romanas cabe citar, en función del número de fragmentos contabilizados, la presencia de THS precoz o sigillatas de imitación de tipo "Peñaflor", lucernas, recipientes de paredes finas y, por último, terra sigillata.

\subsubsection{TSH precoz o sigillatas de imitación de tipo "Peñaflor"}

Constituye uno de los conjuntos más numerosos documentados en el yacimiento, con un total de 56 fragmentos, destacando fuertemente su abundancia frente a otro tipo de cerámicas romanas como la terra sigillata o las paredes finas. Hemos optado por esta denominación aunque dentro de la bibliografía podemos encontrar diversas opciones: "barniz rojo tardío", "barniz rojo julioclaudio", "cerámicas béticas de imitación tipo Peñaflor" o "imitaciones de vajillas de mesa" por citar sólo unas cuantas (Serrano Ramos 1999: 231). Se trata de una producción cada vez mejor conocida y sistematizada, con una serie de características comunes bien definidas desde el punto de vista tecnológico que han permitido su individualización. Supera los objetivos del presente trabajo extendernos en la exposición de estos rasgos o presentar los centros peninsulares de fabricación confirmados y posibles, para lo que remitimos a la bibliografía pertinente ${ }^{13}$. Sí debemos señalar no obstante, por cuanto haremos referencia a ella, la vigencia en términos generales de la tabla tipológica elaborada en 1989 por Martínez Rodríguez ${ }^{14}$, completada años después con nuevas formas detectadas en el yacimiento de Peñaflor (Amores y Keay 1999: 249-250). El repertorio de formas más común suele reducirse al servicio formado por copa y plato, tipos I $(\mathrm{a}, \mathrm{b}, \mathrm{c})$ y II $(\mathrm{b}, \mathrm{c})$ respectivamente, según

13. Una revisión reciente en Bustamante y Huguet (2008: 297-306). 14. Martínez Rodríguez (1989: 60-65). la citada tipología. Las copas (tipo Martínez I) suelen presentar diámetros comprendidos entre los $10-16 \mathrm{~cm}$, perfil troncocónico, pared muy abierta, borde exvasado, carena baja y pie pequeño. Por su parte, los platos o páteras (tipo Martínez II) muestran diámetros que oscilan entre los 14-24 cm, con alta carena y poca altura de la pared; en este caso, los pies destacan por estar bien desarrollados (Serrano Ramos 1999: 232).

Entre los fragmentos recuperados en la Cueva del Valle destaca el dominio de las copas pertenecientes al tipo I de Martínez, que representa la práctica totalidad de los fragmentos (53), la mayoría de ellos encuadrables en los subtipos IB y IC, siendo difícil la clasificación de algunas piezas. La cronología propuesta para estos subtipos arrancaría en las dos últimas décadas del I a.C., desarrollándose ampliamente durante todo el I d.C., con el periodo de máximo esplendor situado entre Claudio/Nerón, datación que coincide con la información aportada por otros materiales romanos presentes en la cavidad. Únicamente podemos clasificar, en función de su tamaño, tres fragmentos (bases con pie bien desarrollado) dentro del subtipo Martínez II, sin que nos sea posible precisar la variante a la que corresponden.

La presencia de estas producciones en la cavidad encaja con lo que conocemos en niveles de cronologías asimilables presentes en otros enclaves betúricos como Capote (Zarzalejos 2003: 133) o Sisapo (Zarzalejos 1995). En principio, y a expensas de que se confirme o no la existencia de otros centros productores como Cádiz o Mérida, cabe proponer una procedencia bética para todo el conjunto. En todo caso, creemos significativo resaltar el elevado número de fragmentos documentado, en claro contraste con la escasa presencia de sigillatas, circunstancia debida quizá al menor coste de las cerámicas tipo Peñaflor. Este hecho aporta una información significativa sobre las poblaciones receptoras de estas piezas. De igual modo, su fuerte presencia en este sector de la comarca de La Serena coincide con la aparición mayoritaria de estas producciones en muchos de los distritos mineros peninsulares (Bustamante y Huguet 2008: 305) y se aviene bien con la riqueza minera (mineralizaciones de cobre, plomo y plata) atribuida tradicionalmente a este territorio.

\subsubsection{Lucernas}

Constituyen un conjunto también numeroso con un total de 30 fragmentos documentados si bien presentan un estado de conservación deficiente que dificulta la identificación de tipos. No se ha encontrado ningún ejemplar completo. Casi todos los fragmentos (27) 


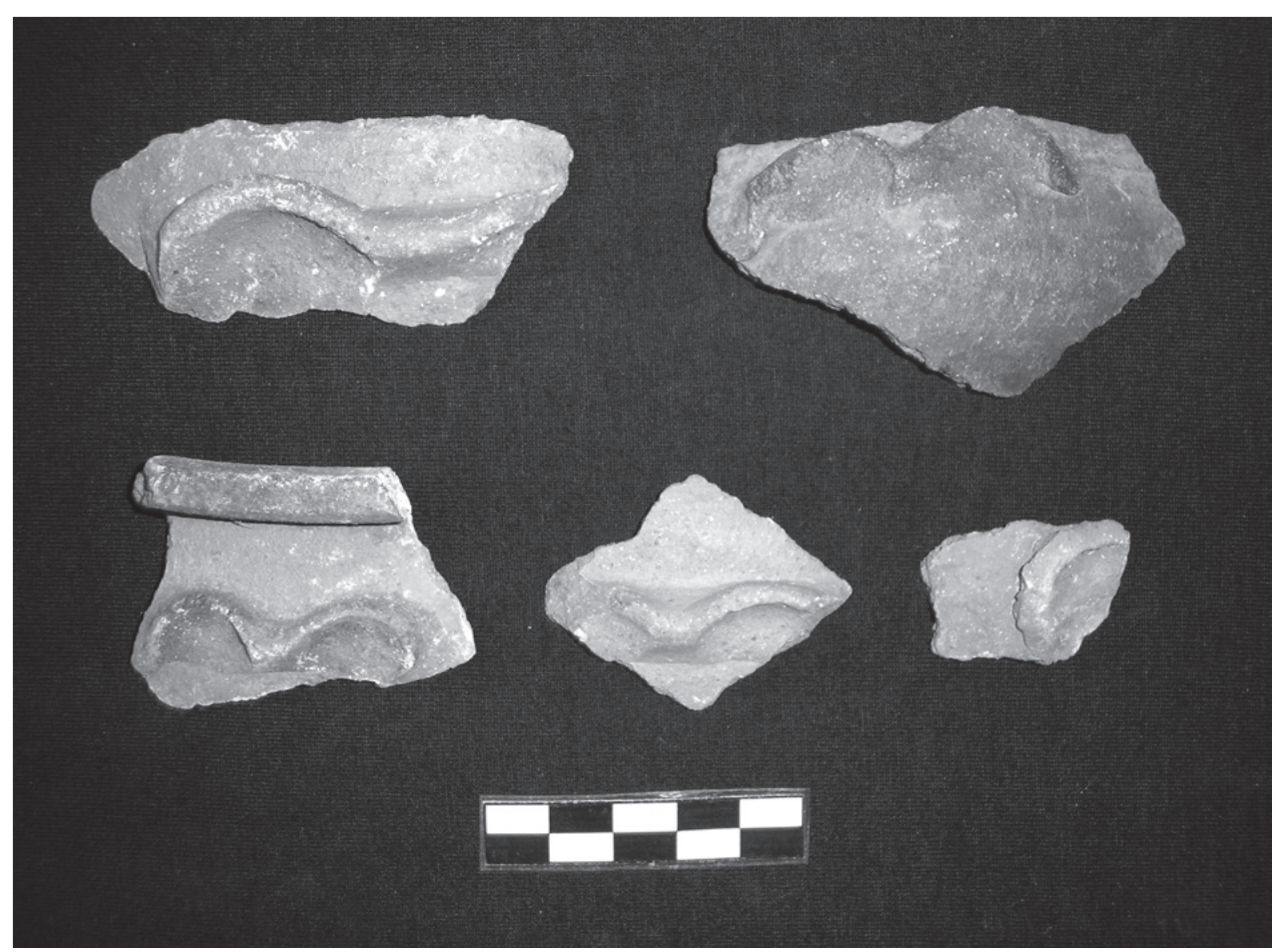

Figura 11. Cerámica común con decoración plástica aplicada procedente de la campaña de prospección de 1999 (fotografia Rebeca Cazorla).

corresponden a lucernas de pasta blanquecino-amarillenta, muy porosa, de tacto áspero y que, en caso de haberlo tenido, no conservan restos de engobe. La mayoría corresponden a distintas partes del depósito, sin que podamos precisar más rasgos significativos; al menos cinco a bases y tres a distintos discos de lucerna: uno de ellos sin decoración conservada mientras que los dos restantes presentan una característica venera $\left(\right.$ motivo $^{\circ}$ 153, clasificación de Bailey) y moldura doble. El fragmento restante corresponde a una piquera o rostrum triangular, sólo conservada parcialmente. Frente a estas lucernas de pasta blanquecino-amarillenta es posible diferenciar tres pequeños fragmentos de diferentes orlas, una de ellas estrecha y horizontal, que presentan una pasta algo más fina, de color blanco y un característico engobe espeso y anaranjado en superficie.

En espera de los resultados que arroje el análisis de pastas, actualmente en curso, no queremos dejar de señalar en esta primera aproximación ciertos aspectos que se derivan del análisis macroscópico de esta treintena de fragmentos. Por lo general las características del primer grupo (pastas de color blanquecino-amarillento, bien depuradas, de tacto arenoso y ligeramente áspero y con algunas pequeñas vacuolas) encajan bien con las denominadas lucernas tipo Andújar, una de las producciones de lucernas hispanas altoimperiales mejor conocida. En el mismo sentido apunta la presencia de dos fragmentos de disco decorados con una venera, único motivo documentado durante los trabajos de prospección. Por lo general, se trata como decimos de un motivo bien conocido y ampliamente representado, incluido dentro de las representaciones faunísticas, en concreto dentro del subtipo destinado a los crustáceos. Autores como Ángel Morillo han señalado la posibilidad de que la concavidad del disco de las lucernas, especialmente adecuada para la representación de un elemento como la venera, junto con su volumen y facilidad de ejecución, pueda explicar el éxito que tuvo este motivo entre los alfareros lucernarios (Morillo 1999: 244). Las variantes de este tipo son múltiples, 
derivadas del número, la anchura y disposición de los gallones: desde las representaciones más naturalistas a veneras con gallones cóncavos o convexos con o sin charnela. Habitualmente se señala el siglo I d.C. como periodo de máximo esplendor de este tipo de motivos sobre lucernas de volutas, aunque su perduración en época bajo-imperial está constatada. Los paralelos peninsulares son, como cabría esperar, abundantes: Andújar, Córdoba, depósito alto-imperial de Capote (Badajoz), Mérida, La Bienvenida (Ciudad Real), Herrera de Pisuerga, Cueva de la Barrera Blanca (Luyego), Conimbriga o Évora, por citar sólo algunos de ellos ${ }^{15}$. Este motivo decorativo aparece mayoritariamente sobre lucernas derivadas de la Dressel 3- Sotomayor D-I (Rodríguez Martín 2002: 24), pudiendo aparecer también sobre otras tipologías, caso de la Dressel 9A-Loeschcke IA de Capote (Morillo 2003: 72). En lo que respecta a la cronología existen diferentes propuestas que abarcan fundamentalmente desde finales de la República e inicios de época augústea hasta comienzos del II d.C., si bien para nuestro caso, y en virtud de los paralelos más próximos (Mérida, Capote, Torreáguila o La Bienvenida) cabría pensar en una cronología Julio-Claudia, que se extendería quizá hasta época flavia. No es posible proponer una procedencia exclusivamente bética para este conjunto de lucernas de la Cueva del Valle ya que, si bien encajan como venimos diciendo dentro de la denominación genérica de lucernas tipo Andújar, recientes estudios han confirmado la existencia de otros centros productores de lucernas de este tipo tanto en la capital bética como en Mérida ${ }^{16}$.

Menos problemas de atribución presentan los tres pequeños fragmentos de orla lisa con moldura simple, cuyas características nos permiten proponer como fabricantes de estas lucernas a los alfares de Emerita $\mathrm{Au}$ gusta. La pasta es fina, de color blanquecino y corte rugoso, con un engobe de color anaranjado (con ciertas irisaciones en uno de los tres fragmentos) bien conocido en los hallazgos de materiales que proporcionan los distintos depósitos del solar emeritense. No nos es posible especificar su clasificación tipológica, dadas sus reducidas dimensiones y la ausencia de suficientes características diagnósticas. La cronología de estas lucernas no puede ser, por tanto, precisa aunque sí sabemos que este tipo de producciones de los alfares emeritenses son casi exclusivas del siglo I d.C. ya que a partir del primer cuarto del siglo II d.C. van dejando de fabricar este tipo de lucernas en pasta de paredes finas en favor de las realizadas en cerámica común. Sabemos

15. Vid. Rodríguez Martín (2005: 27 y ss. También Morillo (1999). 16. Rodríguez Martín (1996). además que los talleres emeritenses comienzan a funcionar a partir de Claudio-Nerón, época en la que llegarían a la ciudad los primeros alfareros (Rodríguez Martín 2002: 210).

A falta de conocer los resultados que aporten los análisis de pastas y dado que estamos manejando materiales de prospección, resultaría aventurado intentar valorar la contemporaneidad o no de ambos conjuntos lucernarios, si bien parece claro que compartirían, al menos parcialmente, un mismo momento cronológico. Sí creemos significativo resaltar la circunstancia de que el $90 \%$ de los fragmentos de lucernas recuperados encaje con las producciones alto-imperiales denominadas de tipo Andújar.

\subsubsection{Recipientes de paredes finas}

Durante los trabajos de prospección se recuperaron un total de 24 fragmentos correspondientes a distintos recipientes realizados en paredes finas. Seis de ellos no presentan decoración alguna, tres de los cuales corresponden a la parte superior y borde de un recipiente. Sus dimensiones son tan reducidas que no es posible precisar las formas. Las pastas presentan una notable variedad, con tonalidades que van del amarillento al pardo mate, pasando por fragmentos de pasta color anaranjado. Ninguna conserva restos de engobe.

Más información nos proporcionan los 18 fragmentos restantes, todos ellos con decoración, así como una importante variedad en las pastas y acabados. Los tipos decorativos documentados son los siguientes:

decoración arenosa: tres pequeños fragmentos de borde, pasta de color blanquecino-amarillento, de corte rugoso, con engobe anaranjado en dos de los casos y ocre-amarillento en otro de ellos. Los tres pueden ser clasificados sin problemas en la forma Mayet XXXVII, con el característico borde fino en forma de bastoncillo. Esta decoración es típica de los talleres béticos y de la Graufesenque, aunque sabemos que fue producida también en alfares emeritenses. La cronología propuesta para estos vasos varía ligeramente si bien no parece superar los comienzos de época flavia: Las producciones béticas más antiguas arrancarían de época de Claudio-Nerón, desapareciendo hacia el reinado de Vespasiano. La cronología propuesta por Mayet (Tiberio-Claudio hasta época flavia) coincide parcialmente con la que ofrecen los estratos de la villa romana de Torre Águila (Badajoz), pudiendo continuar aquí hasta comienzos del siglo II d.C. (Rodríguez Martín 1996: 46). 


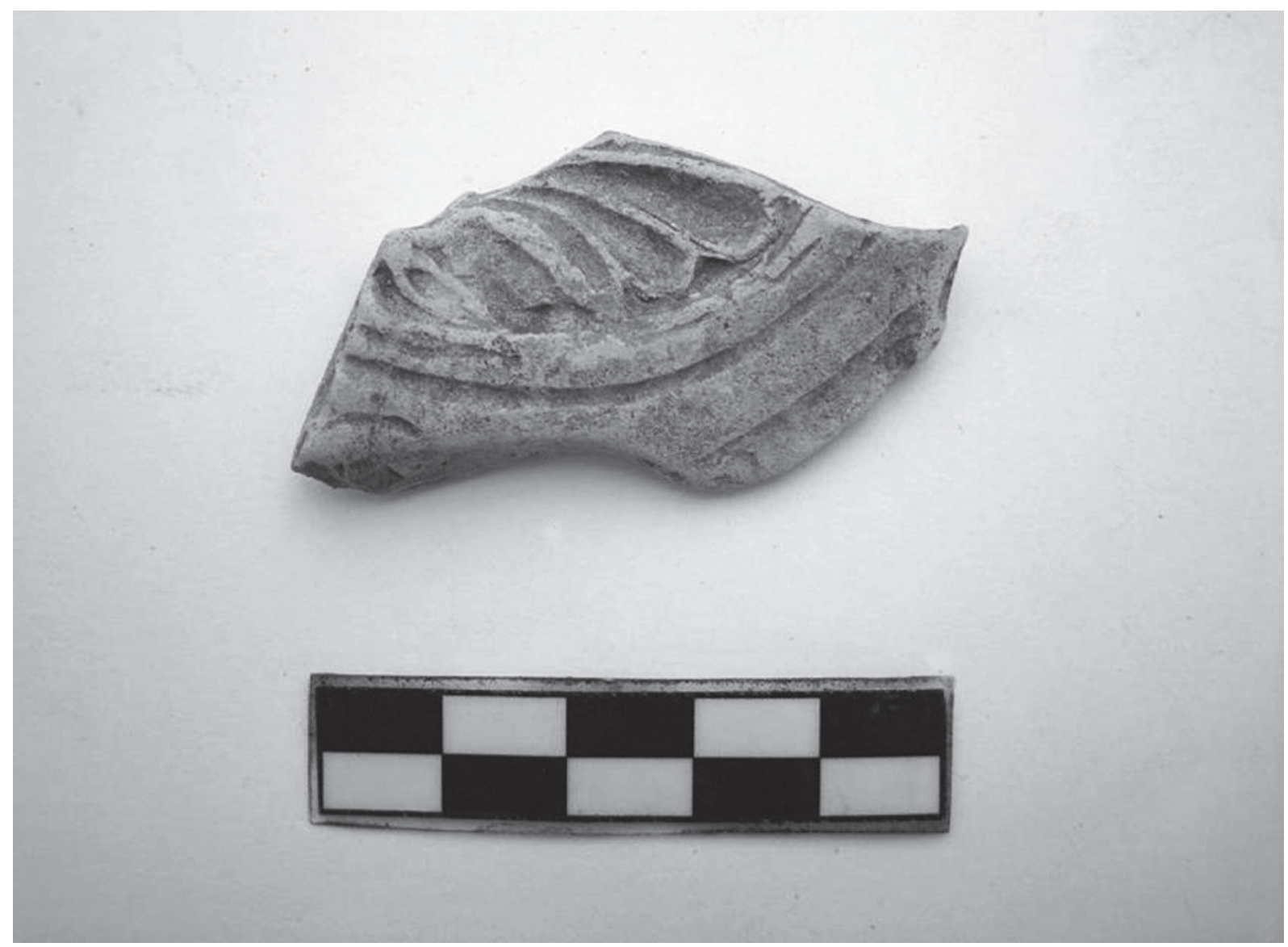

Figura 12. Fragmento de lucerna tipo Andújar con decoración de venera procedente de la campaña de prospección de 2006 (fotografía Rebeca Cazorla).

decoración a base de lúnulas: un fragmento de galbo de buenas dimensiones; pasta de color amarillento con engobe espeso de color ocre-anaranjado. No es posible identificar la forma aunque en Mérida aparece en las formas Mayet XLIII y XLIV, consideras por la autora como una de sus formas más características. Cuenta con abundantes paralelos fundamentalmente dentro del ámbito lusitano (Olivenza, Elvas, Conimbriga o Miróbriga), pero también en la Bética (Jerez de los Caballeros y Munigua) o en Mallorca (Rodríguez Martín 1996: 17).

decoración a ruedecilla: tres pequeños fragmentos, uno correspondiente a un borde mientras que los dos restantes son galbos; pasta color blanquecino-amarillento, con restos de engobe acastañado y anaranjado. Decoración muy típica en los talleres emeritenses, aporta cronologías de época de Tiberio-Claudio.

decoración vegetal: Dos pequeños fragmentos, correspondientes a la parte superior de un recipiente. Pasta pardo-grisácea en uno de ellos y ocre-amarillenta, con engobe anaranjado la segunda. En uno de los fragmentos se aprecia el tallo de una rama alargada y una línea de perlas discontinuas en la parte superior, cerca del borde. En el otro parece apreciarse el arranque de una hoja de agua. Este tipo de decoración es frecuente sobre formas Mayet XLIII y XLIV, si bien no podemos precisar nuestras formas dado el reducido tamaño de los fragmentos.

decoración mediante mamelones: tres fragmentos de pasta color ocre-blanquecina, con engobe de color anaranjado, bastante bien conservado, con ligeras irisaciones en dos de los fragmentos. Uno de ellos corresponde probablemente al borde de un recipiente tipo Mayet XLIII, forma que la autora considera como una de las más típicas de los talleres emeritenses y fecha en la segunda mitad del siglo I d.C.

decoración de espinas realizada a la barbotina: seis fragmentos, uno de ellos de buenas dimensiones, 
que parece corresponder a la parte central de un bol con tendencia globular, quizá Mayet XXXVII o $\mathrm{XL}$. Pastas de color anaranjado hasta pardo, sin que se aprecien trazas de engobe; corte recto. Probable procedencia bética.

\subsubsection{Terra sigillata}

Corresponden a esta categoría un total de siete fragmentos de terra sigillata de reducidas dimensiones, por lo que no es posible precisar la forma de los recipientes a los que pertenecían salvo en dos casos. Seis de los fragmentos corresponden a terra sigillata hispánica, y no presentan decoración alguna. Sólo nos ha sido posible identificar una única forma entre las producciones hispánicas: un pequeño fragmento liso de plato tipo Drag.15/17. El fragmento restante, decorado, corresponde a un cuenco Drag.29 realizado en terra sigillata sudgálica y cuya decoración consiste en un ave de perfil pasante a la izquierda, enmarcado por varias líneas verticales onduladas a ambos lados del animal. Las formas documentadas presentan una amplia cronología, especialmente el plato, mientras que el cuenco carenado, si atendemos a la cronología establecida para esta producción sudgálica decorada, se situaría entre el 10-90 d.C.

\subsection{Materiales votivos}

\subsubsection{Vasitos cultuales}

Incluimos en esta categoría una docena de recipientes cerámicos de diversa tipología, realizados a mano y caracterizados por presentar arcillas poco depuradas, con desgrasantes silíceos y de cuarzo de grosor fino a medio, y cocciones en ambientes reductores. Las pastas son toscas, de color pardo a grisáceo, con algunas nubes de cocción. Durante la prospección superficial de 1999 se recuperaron hasta doce vasitos cultuales, algunos casi completos. La mayoría reproducen formas sencillas, como cuencos y cubiletes de paredes rectas, todos éstos con bases planas de diámetros comprendidos entre 1 y $2,5 \mathrm{~cm} \mathrm{La}$ altura conservada ronda los 4-5 cm. Uno de los vasitos reproduce la forma de un anforisco, con la característica base pivotada, destacando tanto su modelado irregular como la abundancia de desgrasantes de cuarzo gruesos.

Las pequeñas dimensiones de estos materiales impiden otorgarles un uso funcional práctico (Celestino Pérez 1997: 374), permitiéndonos interpretarlos como vasitos votivos que se depositarían a modo de ofrenda en el santuario. Este tipo de hallazgos cuenta con algunos paralelos peninsulares, como los vasitos en miniatura documentados en el departamento 14 del poblado del Puntal dels LLops ${ }^{17}$, los pequeños platos denominados tipo "margarita" de Cancho Roano (Maluquer de Motes 1981) o las pequeñas ánforas tubulares del santuario de La Algaida (Cádiz) (Corzo 1991). El fenómeno de la miniaturización de objetos cotidianos diversos aparece asociado comúnmente a los depósitos votivos, las ofrendas en los santuarios o los ajuares funerarios, y es bien conocido en el mundo mediterráneo (EdlundBerry 2004). Mediante la reducción de su tamaño se indica que el objeto no puede cumplir su función habitual al tiempo que es dotado de un significado extrahumano, destinado a servir como ofrenda cultual (Segarra 1997: 295). Este distanciamiento de la esfera cotidiana no supuso el olvido de las formas habituales del repertorio cerámico; al contrario, entre algunos de los vasitos votivos documentados en la cueva se han detectado formas de cronología bastante anterior ya documentadas, por ejemplo, en el palacio-santuario de Cancho Roano, caso de las ánforas púnicas tipo CR-1 (Celestino Pérez 1997: 375). Parece significativa además la presencia de vasos que reproducen a la perfección los tipos de los caliciformes, uno de los materiales que mejor caracterizan muchas de las cuevas-santuario peninsulares.

\subsubsection{Exvotos}

La prospección superficial realizada en los años 1999 y 2006 ha permitido recuperar un importante conjunto de exvotos, hasta un total de 26 piezas, todas ellas realizadas a mano utilizando la arcilla como materia prima. Si bien estos materiales carecen de un contexto estratigráfico preciso, habiendo sido recogidos tanto en el interior de la propia cavidad como en la explanada inferior situada bajo los pies de la misma, no deja de ser significativo el elevado número de piezas recuperadas, máxime si pensamos en las distintas rebuscas y visitas con recogidas de material de que ha sido objeto desde antiguo el lugar. Esto puede dar idea del volumen de ofrendas que debió recibir la cueva durante el periodo de vigencia de la misma como santuario.

Así, nos encontramos con un conjunto bastante homogéneo en cuanto a configuración y características de elaboración: las 26 piezas corresponden a fragmentos

17. En dicha estancia, interpretada como una probable capilla doméstica se localizaron numerosos microvasos: platos, pateras y caliciformes (Bonet y Mata 2002: 84). 
de exvotos antropomorfos que representan figuras tanto masculinas como femeninas, sin que se haya localizado ninguna completa en estas prospecciones. Todos los fragmentos están modelados a mano y realizados en arcilla común, y suelen presentar abundantes desgrasantes de mica y/o cuarzo de grosor fino a medio; siempre son piezas macizas, cocidas en ambientes oxidantes por lo que presentan tonalidades que van del anaranjado al ocre, en ocasiones con nubes de cocción. La elaboración de todos estos exvotos denota una gran sencillez, limitándose el artesano a representar los detalles anatómicos más destacados: los torsos muestran una clara tendencia rectangular, con la parte posterior alisada, indicándose con claridad el sexo de la figura; las extremidades a menudo son simples cilindros modelados sobre los que se aplican en algunas ocasiones pequeños botones de arcilla para representar la rodilla o los tobillos. La única cabeza del conjunto (CV/06/14), masculina, parece mostrar un mayor grado de detalle en la representación de los distintos elementos que conforman el rostro. Incisiones, digitaciones y la aplicación de botones o perlas de arcilla sobre la pieza constituyen pues los mecanismos más frecuentes para la representación de los detalles en estas terracotas (Figs. 14 y 15).

Dentro de este conjunto llama la atención la elevada proporción de extremidades inferiores (16), máxime si lo comparamos con los dos únicos torsos recuperados (CV/06/1 y CV/06/2); cabe pensar que quizá las reducidas dimensiones de las primeras hayan facilitado su conservación hasta nuestros días. No obstante, dada la morfología de todas ellas no creemos que se trate de exvotos anatómicos, sino de figuras antropomorfas completas conservadas fragmentariamente. Los dos torsos a los que acabamos de hacer referencia, uno femenino y otro masculino, presentan varios detalles significativos; de un lado, el hecho de que se representen figuras desnudas, sin ningún tipo de vestimenta u adorno que los diferencie o individualice; por otro, la clara intención del artesano de mostrar el sexo de la misma, siendo éste casi el único rasgo anatómico representado. Sus dimensiones $(8,2 \times 4,2$ x 2,3 cm y 5,6 x 3,4 x 1,5 $\mathrm{cm}$ respectivamente) nos hacen suponer que las figuras completas debían presentar un buen tamaño, próximo a los $15 \mathrm{~cm}$ de altura. Mayor grado de detalle muestra, como avanzábamos líneas atrás, la cabecita masculina sin cubrir (dimensiones: 4,2 × 2,7 × $2 \mathrm{~cm}$ ): sobre el rostro, de tendencia elíptica, se aplicaron los distintos rasgos (cejas, ojos, nariz...) destacando el fuerte mentón, muy marcado, así como la ausencia de representación del cabello.

En resumen, nos encontramos con un conjunto que presenta unas características comunes como son su
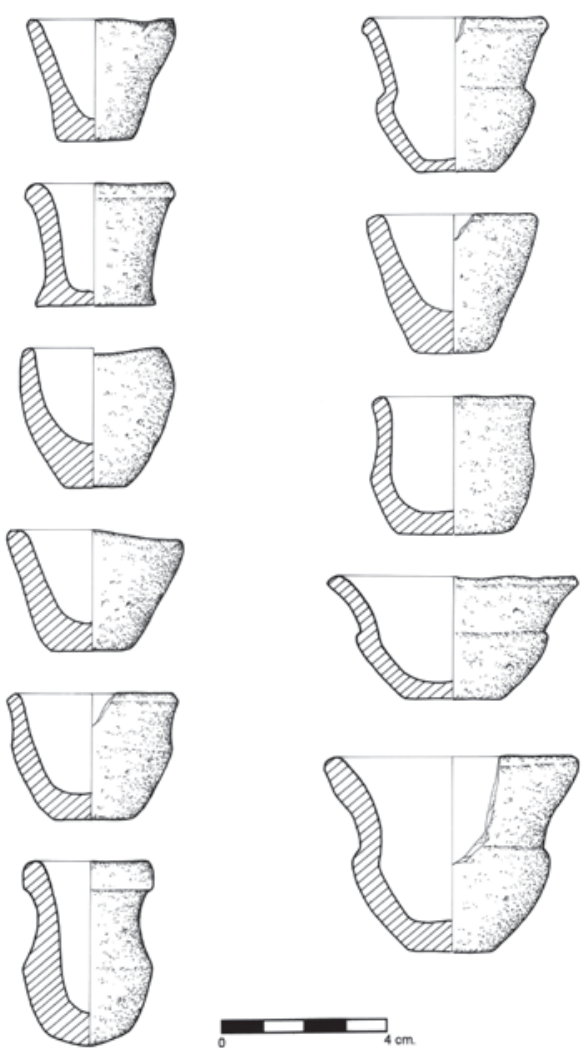

Figura 13. Selección de vasitos cultuales procedentes de la Cueva del Valle (Celestino Pérez 1997).

sencillez, la elaboración a mano o la desnudez de las figuras, sin que se aprecie intento alguno de denotar la posición del oferente. Todas las piezas parecen evidenciar una elaboración muy ágil que podríamos definir como industrial, capaz de abastecer rápidamente a los fieles y personas que se acercasen al lugar, primándose el hecho de la ofrenda de la figura sobre cualquier aspecto estético o de significación social evidenciado a través de la misma. La realización de exvotos antropomorfos desnudos, sea en bronce, piedra o barro, cuenta con buenos paralelos tanto dentro de la península como en el ámbito mediterráneo. Por ceñirnos a los primeros, son sobradamente conocidos los conjuntos de exvotos ibéricos realizados en bronce localizados en los santuarios jienenses de Collado de Los Jardines y Castellar de Santisteban, para los que se ha señalado la circunstancia de que la desnudez constituye la forma correcta de presentarse ante la divinidad (Prados Torreira 1996: 277). Mayores similitudes tanto morfológicas 
como, probablemente, cronológicas, encontramos con el conjunto de terracotas del santuario de La Serreta de Alicante, fechadas entre finales del siglo III a.C. y el I a.C. Estas similitudes son mucho más evidentes en concreto con el grupo IX "figuras de carácter primitivo" establecido por Juan i Moltó (1987-88: 315), diferenciadas por un cierto carácter arcaizante y entre las que encontramos algunos torsos desnudos y con los brazos dispuestos sobre el abdomen. Por otro lado, la abundante presencia de piernas y pies entre los exvotos de la Cueva del Valle ha permitido proponer recientemente la existencia de paralelos también con algunas piezas del santuario de Torreparedones (Córdoba), e interpretadas como posibles exvotos de terracota ofrecidos a la divinidad con el fin de solicitar su protección ante un viaje (Celestino Pérez y Tortosa 2008: 481). Ciñéndonos al ámbito extremeño cabría destacar la proximidad de nuestro conjunto con una terracota realizada a mano localizada en el yacimiento extremeño del Cerro de San Pedro (Valencia del Ventoso, Badajoz) y que ha sido interpretada como una figura femenina (Berrocal-Rangel 1992: 124). Su tosquedad remite igualmente a prototipos indígenas arcaizantes, muy alejados por tanto de las terracotas elaboradas a molde que reproducen tipos iconográficos romanos encontradas también en ese mismo yacimiento o en el depósito alto-imperial de Capote. Igualmente cabe citar, en función de su proximidad tanto formal como geográfica, la presencia de algunas terracotas en el depósito votivo de Garvâo, fechado en el siglo III a.C. (Beirâo 1985-86).

El hallazgo de elementos de carácter votivo constituye uno de principales puntos de partida para acercarnos al complejo mundo de la religiosidad prerromana, sirviendo en no pocas ocasiones como hito cuya presencia permite a los investigadores clasificar un lugar como un santuario o atribuir una funcionalidad religiosa a un espacio doméstico situado en el interior de un poblado. Entre estos materiales votivos juegan un papel destacado los exvotos, bien conocidos en los lugares de culto ibéricos, representándose tanto figuras antropomorfas, como animales y partes anatómicas. Respecto a la materia prima empleada, se conocen ejemplares realizados en piedra (caliza o arenisca), en bronce o en arcilla, como en la Cueva del Valle, habiéndose explicado la elección de uno u otro material en función de su disponibilidad según zonas (Moneo 2003: 360). En el caso del barro parece lógico relacionar su menor coste frente al bronce y la sencillez de su elaboración con su vinculación con cultos de base popular (Fernández Gómez 1988: 143).

La cronología de estos exvotos resulta en ocasiones problemática si valoramos las circunstancias de aparición de muchos de ellos a las que hacíamos alusión antes. Parece existir no obstante cierta unanimidad en torno a la mayor antigüedad de las figuras de bronce; así, algunos exvotos de Collado de los Jardines, santuario con una cronología probable de finales del siglo $\mathrm{V}$ o comienzos del IV a.C. hasta época romana, parecen ser más antiguos que los de Castellar ${ }^{18}$, donde las excavaciones documentan su uso desde finales del siglo IV a.C. y, sobre todo, desde el siglo III a.C. Las fechas disponibles para el santuario de La Luz dan como periodo de máximo apogeo del mismo los siglos III-I a.C. (Ruiz Bremón 1988), hecho que demostraría la amplia pervivencia de la ofrenda de exvotos de bronce en los santuarios peninsulares. Desde el siglo IV-III a.C. en adelante conocemos además santuarios como el Cerro de los Santos (Albacete), El Cigarralejo y la Encarnación (Murcia), y Torreparedones entre otros, donde la piedra fue la materia prima utilizada en la elaboración de los exvotos ${ }^{19}$. Algunos de estos santuarios continuarían también en uso en época plenamente romana.

En lo que respecta a las terracotas, especialmente las figuras antropomorfas, conocen una amplia difusión dentro y fuera del ámbito ibérico con concentraciones significativas de hallazgos en el área levantina y Andalucía central. Entre los santuarios donde se han localizado este tipo de exvotos destacan, junto a la propia Cueva del Valle, Villaricos (Almería), Coimbra del Barranco Ancho (Murcia), La Serreta (Alicante), el depósito de El Amarejo (Albacete), San Miguel de Liria, Castellet de Bernabé, el Puntal dels Llops, La Carraposa o la Cueva de Les Meravelles (Valencia) (Moneo 2003: 366-67). Esta vasta dispersión se explica en parte por la propia amplitud del mismo término, que da cabida a piezas muy variadas, desde exvotos realizados a mano o a molde, pebeteros en forma de cabeza femenina, cabezas votivas o terracotas de iconografía ya propiamente romana.

Si nos ceñimos a las cuevas-santuario el número de ejemplos se reduce, ya que sólo conocemos hasta el momento dos yacimientos donde se han depositado exvotos de barro realizados a mano: Les Meravelles y la propia Cueva del Valle, aunque esta última, dadas sus características y dimensiones, no parece encajar

18. En todo caso, parece existir una clara evolución tipológica (y cronológica) de los exvotos realizados en bronce, donde los exvotos esquemáticos y anatómicos parecen responder a una cierta "popularización" de este tipo de ofrendas, documentada a partir del siglo III a.C. y, sobre todo, durante la Baja Época (Prados Torreira 1994:137).

19. Chapa y Martínez Navarrete (1990: 103-111); Ruano Ruiz (1988: 262-265); Ruano y San Nicolás (1990: 101-107); Morena López, (1989: 47-48); Cunliffe et alii (1993: 519-528); Marín y Belén (1987: 84-85). 

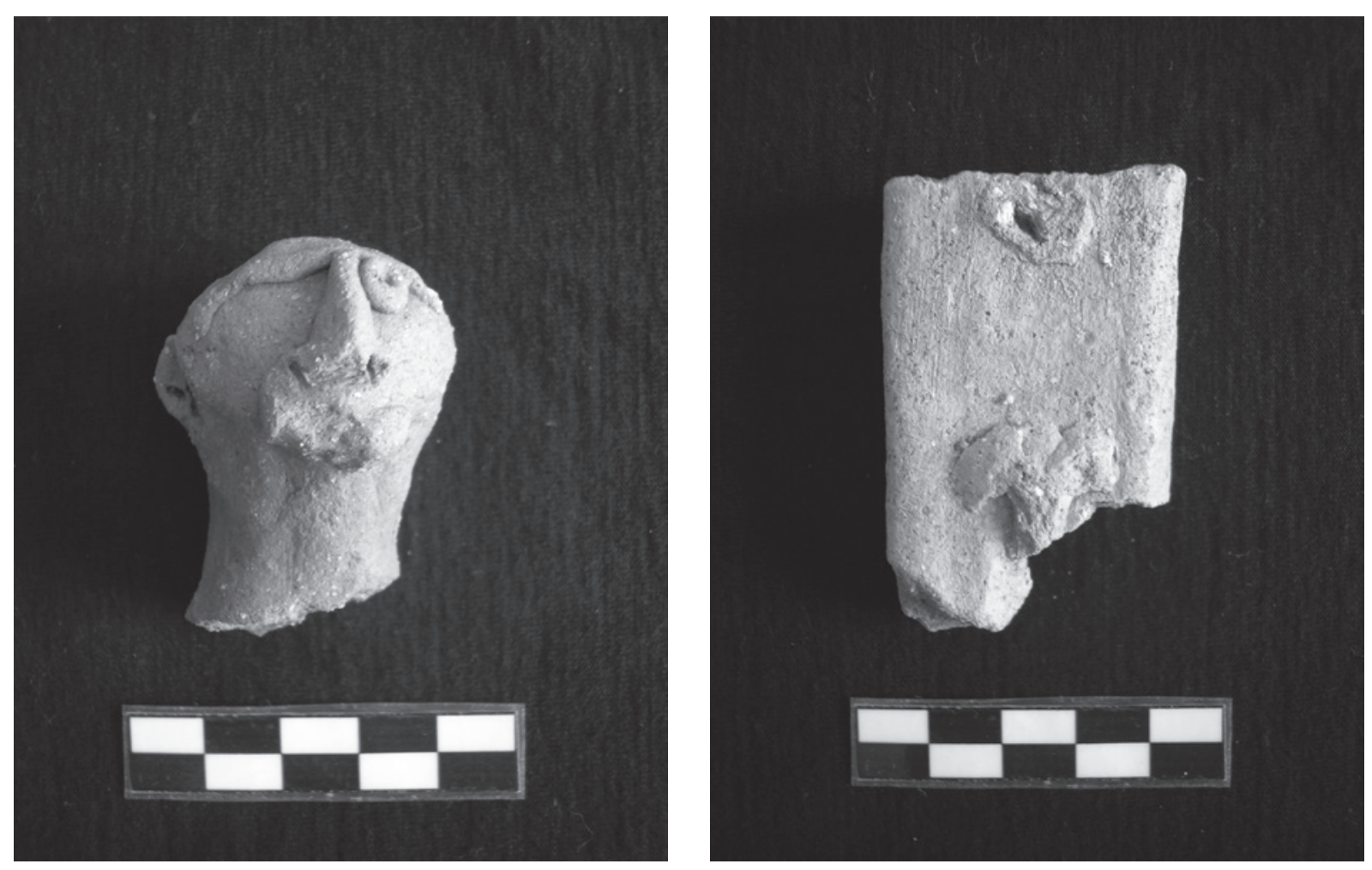

Figuras14 y 15. Exvotos antropomorfos procedentes de la campaña de prospección de 2006: cabeza (CV/06/14) y torso (CV/06/2) masculinos (fotografía: Rebeca Cazorla).

plenamente en dicha categoría. En la Cueva de Les Meravelles (Gandía, Valencia), recogida tanto en los trabajos de Tarradell (1973) como en los de Gil-Mascarell (1975), se documentaron un total de cinco exvotos realizados en arcilla: dos de ellos representan la mitad inferior de dos piernas humanas, otro es una pequeña estatuilla en bulto redondo que representa el torso de un varón, y los dos restantes son dos cilindros, uno macizo y otro hueco, con estrechamientos en la parte superior que representan esquemas de cabezas humanas (González Alcalde 2003: 222-223). Esta distribución se amplía ligeramente si consideramos además los exvotos realizados en piedra, con la inclusión de una pequeña cabeza humana realizada en piedra caliza localizada en La Cueva de la Murcielaguina (Priego de Córdoba) (Vaquerizo 1985; id. 1997), o los propios santuarios rurales en un sentido más amplio, incluyendo los exvotos de bronce y arcilla de Collado de los Jardines y Castellar de Santisteban. Igualmente cabría citar, ya dentro del ámbito púnico, el santuario ebusitano de Es $\mathrm{Cu}$ yram, dedicado a la diosa Tanit y fechado entre el siglo IV a.C. y el siglo II a.C., donde la ofrenda de exvotos de terracota realizados a molde, fundamentalmente figuritas acampanadas y pebeteros en forma de cabeza femenina, parece haber constituido una parte importante del culto (Aubet 1982).

Según lo que acabamos de exponer, únicamente parece posible convenir la mayor antigüedad de los exvotos realizados en bronce, presentes quizá desde el periodo Ibérico Antiguo, aunque su pervivencia y popularización durante el Ibérico Pleno y la denominada Baja Época convive ya con la presencia de exvotos realizados en piedra y terracota. Estos últimos son los que parecen alcanzar cronologías más tardías, documentándose en contextos romano-republicanos e incluso imperiales. Es el caso de muchas de las terracotas localizadas en la actual región extremeña, a algunas de las cuales hemos tenido ocasión de aludir ya. Destaca en este punto el importante conjunto documentado en el depósito alto-imperial de Capote, fechado hacia el 45 d.C. si bien la fecha de fabricación de los materiales contenidos en dicho depósito se situaría en el periodo comprendido entre el 29 a.C. y el 27 d.C. Estas terracotas realizadas a molde reproducen claramente tipos iconográficos itálicos aunque tanto la materia prima como los moldes empleados evidencian una fabricación 
provincial. La interpretación propuesta para este conjunto de exvotos prima la funcionalidad de las piezas esto es, su deposición como ofrendas, frente a la iconografía que representan y que quizá ocultase a alguna divinidad indígena lusitana (Blech 2003: 53). Las características de este conjunto de terracotas, muy similares a las localizadas en el yacimiento pacense del Cerro de San Pedro (Gómez-Pantoja y Prada Gallardo 2000) ofrecen, al igual que su cronología (mediados del siglo I d.C.) un contrapunto interesante de cara a la valoración de los exvotos de la Cueva del Valle, sobre la que volveremos más adelante.

\section{RECAPITULACIÓN Y CONCLUSIONES}

Analizando la bibliografía disponible sobre los lugares de culto ubicados en cuevas y abrigos predominan las referencias relativas al levante peninsular, ámbito al que se creía restringido el fenómeno de las cuevas-santuario durante la década de los años 60 y 70 del pasado siglo. Parece evidente además, como ya intuyera la Dra. Lucas (1981), que esta cierta concentración era debida más al desigual ritmo de avance de la investigación que a particularidades de tipo local en el plano religioso. Así, la publicación de nuevos estudios y la revisión de yacimientos ya conocidos con anterioridad han permitido documentar la existencia de lugares de culto con algunas características asimilables al conjunto de cuevas levantinas en diversos puntos de la geografía peninsular. Nos encontramos por tanto con un fenómeno que conoce una dispersión mucho más amplia de lo inicialmente estimado y un término, el de cueva/abrigo-santuario que puede albergar una extensa gama de variantes.

La amplitud de este fenómeno, y en general, la presencia de santuarios naturales enclavados en determinados elementos geográficos singulares tales como grutas, bosques, fuentes o promontorios, cuenta con múltiples paralelos tanto en el Mediterráneo occidental como oriental, con una cronología extraordinariamente dilatada. No pretendemos ser exhaustivos en este punto, objetivo que superaría claramente la finalidad del presente trabajo, sino que nos limitaremos a citar algunos contextos culturales extrapeninsulares similares con el fin de ilustrar brevemente esa densidad de hallazgos a la que hemos aludido. Por otro lado, muchos de estos paralelos ya han sido discutidos en recientes trabajos de conjunto (Moneo 2003: 301). Son conocidas numerosas cuevas en el Sur de Francia, asociadas a menudo a cursos de agua, donde se depositaron diversos materiales a modo de ofrenda desde el Bronce Final y los inicios de la Edad del Hierro. Exvotos que representan figuras tanto masculinas como femeninas se situaron entre los huecos de la roca en la Cueva de Eileithyia en Tsoutsouros (Creta). Bien conocida es también la Cueva Coricia, recogida por Pausanias en su Descripción de Grecia (10.32.2), donde se rendía culto al dios Pan y a las ninfas. Excavada en 1969 por un equipo francés, cabe destacar el abundante material arqueológico recuperado, en particular los millares de figuritas de terracota femeninas de época clásica o la colección de astrágalos utilizados para la adivinación (Pasquier 1977). Numerosas también son las analogías en Etruria y en la Italia meridional; baste citar como muestra la Grotta del Colle, en la región de los Abruzzos, visitada ya desde el Paleolítico Superior y utilizada como santuario desde época helenística. Entre el material votivo hallado destaca la presencia de numerosos fragmentos de cerámica, una pequeña figurita femenina de bronce (interpretada como una representación de la diosa $\mathrm{Ce}$ rria Iovia), cabecitas humanas realizadas en terracota así como diversos exvotos anatómicos de arcilla, fechados hacia el siglo III-II a.C. Significativa es además la presencia en la cavidad de vasos cerámicos miniaturizados, caso de un olpe de apenas $6 \mathrm{~cm}$ de altura realizado en barniz negro (D’Ercole, Orfanelli y Riccitelli 1997: 58-61).

Volviendo al ámbito peninsular resulta evidente que el conocimiento de estos enclaves padece las dificultades inherentes a todo estudio sobre la religiosidad de las poblaciones prerromanas. La aún escasa lista de yacimientos excavados y la indefinición cronológica de muchos de los materiales en ellos localizados ahonda en esta dificultad, al tiempo que permite crear un marco cronológico extraordinariamente amplio (desde el siglo $\mathrm{V}$ a.C. hasta bien entrada la época imperial) para la vigencia de estos santuarios al aire libre. Estas dificultades son aún mayores a la hora de conocer la divinidad o divinidades a las que se rendiría culto en estas cavidades, salvo casos donde las evidencias materiales resultan bastante esclarecedoras, caso de la citada cueva ebusitana de Es Cuyram (Aubet 1969: 61).

Dentro de este conjunto la Cueva del Valle se muestra como un santuario rupestre ciertamente singular. En los estudios específicos sobre estos lugares de culto continúa vigente en términos generales la diferenciación entre cuevas-santuario frente a las cuevas-refugio (Gil-Mascarell 1975; González Alcalde 2003). Bajo la primera denominación se incluirían todas aquellas cavidades localizadas en lugares de orografía abrupta y difícil acceso, y cuyos trazados, subterráneos y complejos, impiden considerarlas como lugares de habitación. Los materiales (vasos caliciformes, cerámicas griegas de importación, restos óseos, elementos metálicos) 
aparecerían en principio en los lugares más inaccesibles y asociados al agua. Las cuevas-refugio por el contrario suelen presentar materiales muy escasos y toscos, y han sido interpretadas como lugares de refugio ocasional, al no cumplir tampoco los parámetros propios de lugares de habitación permanente. Otros autores, en función de la localización, pero sobre todo, de la morfología y dimensiones del sitio distinguen además entre cuevas-santuario y abrigos-santuario (Moneo 2003: 299), donde los segundos se caracterizarían por su menor extensión y por la frecuente aparición en la zona más exterior, normalmente junto a la entrada de la cavi$\mathrm{dad}$, de inscripciones realizadas en caracteres ibéricos y latinos asociadas a pinturas esquemáticas o naturalistas así como grabados rupestres (Pérez Ballester 1992).

$\mathrm{Si}$ atendemos a las características establecidas tradicionalmente para las cuevas-santuario (localización en paisajes abruptos, dificultad de acceso, presencia de materiales significativos, vinculación con cursos de agua próximos, etc.) observamos que muchas de ellas no se cumplen en el santuario pacense. La Cueva del Valle goza evidentemente de una posición destacada sobre su entorno, pero su situación y su propia morfología no implican un difícil acceso, pudiéndose alcanzar con facilidad el sitio ascendiendo desde la ladera del Cerro del Puerto. Sus dimensiones parecen en efecto más propias de un abrigo profundo, circunstancia que diferencia la cavidad frente a muchas de las cuevassantuario levantinas. Respecto a la vinculación con el agua, el curso más próximo es el río Ortigas, sin que la formación cuarcítica donde se sitúa el santuario responda en ningún caso al desarrollo de procesos cársticos, configuración bastante frecuente en este tipo de yacimientos dentro del ámbito levantino. Los materiales documentados en la cavidad constituyen otra diferencia básica, por cuanto no encontramos uno de los elementos considerados habituales como son los vasos caliciformes, al menos no en sentido estricto ya que sí se han encontrado algunos vasos en miniatura realizados a mano que reproducen claramente sus tipos ( $\mathrm{vid}$. $\mathrm{su}$ pra). La presencia de exvotos realizados a mano en arcilla permite establecer un único paralelo hasta el momento, junto con el ya citado santuario de Los Altos del Sotillo, con la cueva valenciana de Les Meravelles, mientras que el numeroso conjunto de cerámica común documentado relaciona el santuario pacense con otros enclaves como la Cova de La Moneda, Cueva Merinel o las Cuevas del Puntal del Horno Ciego. En este sentido optamos también por explicar la presencia de muchas de estas formas como posibles contenedores de ofrendas, dado el escaso valor intrínseco de estas piezas. Igualmente, cabría contemplar la posibilidad de que parte de las mismas respondan a la celebración de ciertos banquetes y comidas en el lugar por parte de los fieles que acudiesen al santuario, hipótesis que quizá pueda integrarse bien con la interpretación de este yacimiento como un lugar de culto de base claramente popular. En todo caso, el importante volumen de material cerámico recuperado establece de nuevo una clara diferenciación frente a otras cuevas-santuario peninsulares.

Ciñéndonos al territorio correspondiente al sector túrdulo de la Beturia, si escasos son los datos de que disponemos acerca del poblamiento o la estructura socioeconómica de estas poblaciones, aún lo son más aquéllos relativos a cuestiones como el mundo funerario o la religiosidad. En los últimos años se han venido produciendo hallazgos en Los Vadillos y Peñón del Pez que han sido relacionados con posibles necrópolis, aunque la mayor parte de las referencias continúan dependiendo de los datos aportados por la necrópolis republicana de Hornachuelos (Rodríguez Díaz 1993: 251). Respecto a las valoraciones sobre el ámbito de las creencias religiosas éstas tienden a limitarse a la constatación a través de testimonios tardíos del culto a divinidades como Adaegina Turobriguense (López Melero 1986) o Sucellus. Ampliando el marco a los límites de la actual región extremeña cabe citar dos enclaves: el abrigo de Monfragüe (Cáceres) y las Cuevas de Fuentes de León (Badajoz). El primero, situado en la ladera suroeste de la sierra del Castillo de Monfragüe, en un macizo de cuarcita junto al río Tajo, presenta un emplazamiento similar y ha sido interpretado como un lugar de culto de larga perduración, quizá vinculado con un culto astral y relacionado probablemente con el poblado situado en la cumbre de dicha sierra (Moneo 2003: 82). Esta interpretación no cuenta por el momento con materiales arqueológicos asociados que permitan corroborarla. Pocos datos conocemos aún acerca de las Cuevas del Agua de Fuentes de León, enclave conocido desde antiguo por sus restos prehistóricos así como por el hallazgo en sus inmediaciones de la basa de una columna estriada, e incluido dentro del catálogo de yacimientos célticos como un santuario romanizado (Berrocal-Rangel 1992: 192). Ambos yacimientos se muestran, en principio, muy diferentes a la Cueva del Valle.

Acerca del conjunto de exvotos antropomorfos realizados en barro documentado en la cavidad, cabe destacar que tanto su número como su factura nos hablan de un culto de base popular en el que la ofrenda de tales exvotos habría de constituir una parte importante. Estos exvotos permitirían establecer una comunicación privada e individual entre el fiel que acudía al santuario y la divinidad receptora de tales ofrendas. Por otro 
lado, resulta evidente el marcado carácter indígena que presentan estas producciones, en fuerte contraste con las terracotas romanas, realizadas a molde, localizadas en contextos geográfica y cronológicamente próximos a la cavidad, como son el depósito alto-imperial de Capote o la posible favissa del Cerro de San Pedro. Esta circunstancia no hace sino subrayar la singularidad a la que hacíamos referencia antes: el volumen de exvotos depositado en este lugar como ofrenda no puede interpretarse como un hecho aislado o fruto de un momento determinado; por el contrario, parece contar aquí con profundas raíces, capaces de "resistir" la romanización formal de estos exvotos, con un posible rechazo en este sentido a la asunción de tipos iconográficos importados, incluso cuando las producciones cerámicas romanas alcanzan un volumen importante en el yacimiento.

Por otro lado, precisar la cronología de este enclave resulta una tarea compleja ya que mientras su propia ubicación y articulación espacial, similar por ejemplo a algunos de los santuarios del Alto Guadalquivir, remite a momentos anteriores al igual que la ofrenda masiva de exvotos que reproducen tipos arcaicos indígenas, la revisión de los materiales que presentamos en este estudio únicamente nos permite confirmar un marco cronológico comprendido entre comienzos del siglo I a.C. y finales del I d.C. En este sentido, las producciones romanas documentadas muestran una gran coherencia aportando cronologías julio-claudias y flavias. No podemos hoy por hoy mantener por tanto el siglo V-IV a.C. como fecha de inicio del culto en este lugar ni enlazar su origen con la destrucción ritual de Cancho Roano, aunque queremos señalar de nuevo la existencia de ciertos nexos entre ambos enclaves (vid. supra), así como su proximidad.

Esta cronología, sujeta a futuras modificaciones conforme avance nuestro estudio, sí es contemporánea a algunos de los recintos-torre situados en el valle medio del Ortigas como son El Tesoro, Cerro Borreguero o el Recinto de Cancho Roano, con los que además comparte un registro material parcialmente similar. Esta posible relación con los recintos-torre como pequeños núcleos que articularían el poblamiento en época tardorepublicana e imperial parece reforzarse si valoramos su cercanía o la visibilidad de que gozaría, a priori, la Cueva del Valle sobre la zona comprendida entre los cursos del Ortigas y el Cagancha, quedando bastante oculto en cambio el cauce del Guadalefra. La ausencia de poblados en extensión cercanos y el estadio aún inicial de nuestra investigación obliga a mantener ciertas cuestiones abiertas, como la posibilidad de que estemos ante un santuario supraterritorial o la valoración del papel jugado por este lugar de culto y por las poblaciones indígenas durante el proceso de romanización de este territorio.

\section{BIBLIOGRAFÍA}

ÁLVAREZ MARTÍNEZ, J.M (1986): “La presencia romana en la Baja Extremadura”, en M. Terán (dir.), Historia de la Baja Extremadura. Tomo I: 88-185. Real Academia de Extremadura de las Letras y las Artes, Badajoz.

ÁLVAREZ MARTÍNEZ, J.M ${ }^{\mathrm{a}}$; DE LA BARRERA, J.L. y VELÁZQUEZ, A. (1985): "El tiempo antiguo", en G. Barrientos, E. Cerrillo y J.Mª Álvarez Martínez (eds.), Historia de Extremadura. Tomo I. La Geografía y los tiempos antiguos: 101-180. Universitas editorial, Badajoz.

AMORES, F. y KEAY, S. (1999): "Las sigillatas de imitación tipo Peñaflor o una serie de hispánicas precoces” en M. Roca y M M $^{\mathrm{a}}$ I. Fernández García (coords), Terra sigillata hispánica. Centros de fabricación y producciones alto-imperiales: 235-256. Universidad de Jaén-Universidad de Málaga.

AUBET SEMMLER, MªE. (1969): La cueva D'Es Cuyram (Ibiza). Publicaciones del Instituto de Arqueología y Prehistoria, Barcelona.

AUBET SEMMLER, Má E. (1982): El santuario de Es Cuieram. Trabajos del Museo Arqueológico de Ibiza 8. Palma de Mallorca.

BEIRÂO, C. DE M. (1985-86): "Um depósito votivo da II Idade do Ferro", Veleia 2-3: 207-222.

BERROCAL-RANGEL, L. (1992): Los pueblos célticos del suroeste de la Península Ibérica. Complutum Extra n 2.

BERROCAL-RANGEL, L. y RUIZ TRIVIÑO, C. (eds.) (2003): El depósito alto-imperial del Castrejón de Capote (Higuera la Real, Badajoz). Memorias de Arqueología Extremeña, 5. Consejería de Cultura, Mérida.

BLANCO FREIJEIRO, A. (1981): "Cancho Roano, un monumento protohistórico en los confines de la antigua Lusitania", Boletín de la Real Academia de la Historia, Tomo 178, cuaderno 2: 225-242.

BLECH, M. (2003): "Las terracotas", en L. BerrocalRangel y C. Ruiz Triviño (eds.), El depósito altoimperial del Castrejón de Capote (Higuera la Real, Badajoz). Memorias de Arqueología Extremeña 5: 53-67. Consejería de Cultura, Mérida.

BONET ROSADO, H. y MATA PARREÑO, C. (2002): El Puntal dels Llops: un fortín edetano. Diputación de Valencia, Valencia.

BUSTAMANTE, M. y HUGUET, E. (2008): "Las cerámicas «Tipo Peñaflor»", en D. Bernal Casasola y A. Ribera i Lacomba (eds. científicos), Cerámicas hispanorromanas. Un estado de la cuestión: 297-306. Servicio de Publicaciones de la Universidad de Cádiz. 
CELESTINO PÉREZ, J. y CELESTINO PÉREZ, S. (2000): Comisión de Antigüedades de la Real Academia de la Historia. Extremadura. Catálogo e Índices. Real Academia de la Historia, Madrid.

CELESTINO PÉREZ, S. (1997): "Santuarios, centros comerciales y paisajes sacros", Quaderns de Prehistòria i Arqueologia de Castelló 18: 359-390.

CELESTINO PÉREZ, S. (2001): "Los santuarios de Cancho Roano: del indigenismo al orientalismo arquitectónico", en D. Ruiz Mata y S. Celestino Pérez (coords.), Arquitectura oriental y orientalizante en la península ibérica: 17-56. CSIC-Centro de Estudios del Próximo Oriente-Instituto de Historia, Madrid.

CELESTINO PÉREZ, S. y TORTOSA ROCAMORA, T. (2008): "Ensayo acerca de la evolución del espacio sagrado y del ritual religioso desde el final del Orientalizante al mundo romano. El ejemplo del Valle del Guadiana (Extremadura)", en X. Dupré, S. Ribichini y S. Verger (eds.), Saturnia Tellus. Definizioni dello spazio consacrato in ambiente etrusco, italico, fenicio-punico, iberico e celtico: 471-488. CNR- Servizio Pubblicazioni, Roma.

CHAPA BRUNET, T. y MARTÍNEZ NAVARRETE, M.I. (1990): "Valoración general de las excavaciones desarrolladas en el Cerro de los Santos (Montealegre del Castillo, Albacete)", Homenaje a J. Molina: 101-111. Murcia.

CORZO SÁNCHEZ, R. (1991): "Piezas etruscas del Santuario de la Algaida (Sanlúcar de Barrameda, Cádiz)”, en J. Remessal y O. Musso (eds.), $L a$ presencia de material etrusco en la Península Ibérica: 399-411. Barcelona.

CUNLIFFE, B.W.; FERNÁNDEZ CASTRO, M.C.; POOLE, C.; BROWN, L.; DAVENPORT, P.; BROOK, I.; PRESSEY, S.; MORENA, J.A. y TORRES, B. (1993): "Torreparedones, poblado fortificado en altura, y su contexto en la campiña de Córdoba. El Proyecto Torreparedones (Baena, Córdoba)", en J. Campos y F. Nocete (coords), Investigaciones Arqueológicas en Andalucía 1985-1992. Proyectos: 519-528. Junta de Andalucía, Huelva.

D'ERCOLE, V.; ORFANELLI, V. y RICCITELLI, P. (1997): "La grotta del colle di Rapino", in A. Campanelli, y A. Faustoferri (eds), I luoghi degli dei. Sacro e natura nell' abruzzo italico: 58-61. Carsa edizioni, Chieti.

EDLUND-BERRY, I.E.M. (2004): "Other votive objects", Thesaurus Cultus et Rituum Antiquorum I: 368-379.

ENRÍQUEZ NAVASCUÉS, J.J. (1995): "Los pueblos prerromanos de Extremadura", en Celtas y Turdulos: la Beturia. Cuadernos Emeritenses 9: 49-76.
FERNÁNDEZ GÓMEZ, F. (1988): “Terracotas turdetanas del Guadalquivir-Corbones", Espacio, Tiempo y Forma, Serie II, Historia Antigua, tomo I: 143-151.

GARCÍA Y BELLIDO, A. y MENÉNDEZ PIDAL, J. (1963): El distylo sepulcral romano de Iulipa (Zalamea). Anejos de AEspA, III. CSIC. Madrid.

GIL-MASCARELL, M. (1975): "Sobre las cuevas ibéricas del País Valenciano: un ensayo de interpretación", Papeles del Laboratorio de Arqueología de Valencia 11: 281-332.

GÓMEZ-PANTOJA, J. y PRADA GALLARDO, A.: (2000): "Las terracotas del Cerro de San Pedro (Valencia del Ventoso, Badajoz)", Hispania Antiqua 24: 383-410.

GONZÁLEZ-ALCALDE, J. (2002): Las cuevas santuario y su incidencia en el contexto social del mundo ibérico. Tesis Doctoral inédita. Universidad Complutense de Madrid.

GONZÁLEZ-ALCALDE，J. (2003): "Cuevas-refugio y cuevas-santuario en Castellón y Valencia: espacios de resguardo y entornos iniciáticos en el mundo ibérico", Quaderns de Prehistòria i Arqueologia de Castelló 23: 187-240.

GONZÁLEZ-ALCALDE, J. y CHAPA BRUNET, T. (1993): "Meterse en la boca del lobo. Una aproximación a la figura del carnassier en la religión ibérica", Complutum 4: 169-174.

GRANADOS, L.F. (2007): "Entorno geológico de los yacimientos arqueológicos de Cancho Roano y Cueva del Valle". Informe inédito.

GRAU MIRA, I. (2000): "Territorio y lugares de culto en el área central de la Contestania ibérica", Quaderns de Prehistòria i Arqueologia de Castelló 21: 195-226.

JUAN I MOLTÓ, J. (1987-88): "El conjunt de terracotes votives del santuari ibèric de la Serreta (Alcoi, Cocentaina, Penàguila)", Saguntum 21: 295-329.

LÓPEZ MELERO, R. (1986): "Nueva evidencia sobre el culto de Ategina: el epígrafe de Bienvenida", Primeras Jornadas sobre Manifestaciones Religiosas en la Lusitania: 93-112. Cáceres.

LORRIO ALVARADO, A.J.; MONEO, T.; MOYA; F.; PERNAS, S. y SÁNCHEZ DE PRADO, $M^{a} D$. (2006): "La Cueva Santa del Cabriel (Mira, Cuenca): lugar de culto antiguo y ermita cristiana", Complutum 17: 45-81.

LUCAS, M ${ }^{a}$ R. (1981): "Santuarios y dioses en la Baja época ibérica", La Baja Época de la Cultura Ibérica. Actas de la mesa redonda celebrada en conmemoración del $10^{\circ}$ aniversario de la Asociación Española de Amigos de la Arqueología: 233-293.

MALUQUER DE MOTES, J. (1981): El santuario protohistórico de Zalamea de La Serena, Badajoz. Vol. 
I, 1978-1981. Programa de Investigaciones Protohistóricas IV. Institución Milá y Fontanals, Universidad de Barcelona. Barcelona.

MARÍN CEBALLOS, M.C. y BELÉN, M. (1987) "Nuevos exvotos ibéricos de la provincia de Jaén", Anales de la Universidad de Cádiz 4: 84-85.

MARTÍ BONAFÉ, Ma A. (1990): "Las cuevas del Puntal del Horno Ciego. Villagordo del Cabriel. Valencia", Saguntum. Papeles del Laboratorio de Arqueología de Valencia 23: 141-182.

MARTÍNEZ PERONA, J.V. (1992): “El santuario ibérico de la Cueva Merinel (Bugarra): en torno a la función del vaso caliciforme", Estudios de arqueología ibérica y romana: homenaje a Enrique Pla Ballester. Serie Trabajos Varios S.I.P. 89: 261-282.

MARTÍNEZ RODRÍGUEZ, F. (1989): “Las cerámicas béticas de imitación tipo Peñaflor: bases para el estudio de un nuevo grupo cerámico de época altoimperial", Boletín de la Asociación de Amigos de la Arqueología 26: 60-65.

MATA PARREÑO, C. y BONET ROSADO, H. (1992): "La cerámica ibérica: ensayo de tipología", Estudios de arqueología ibérica y romana: homenaje a Enrique Pla Ballester. Serie Trabajos Varios S.I.P. 89: 117-174.

MAYORAL HERRERA, V.; CERRILLO CUENCA, E. y CELESTINO PÉREZ, S. (2009): "Métodos de prospección arqueológica intensiva en el marco de un proyecto regional: el caso de la comarca de $\mathrm{La}$ Serena (Badajoz)", TP 66 (1): 7-26.

MONEO, T. (2003): Religio ibérica: santuarios, ritos $y$ divinidades (siglos VII-I a.C.). Real Academia de la Historia, Madrid.

MORENA LÓPEZ, J.A. (1989): El santuario ibérico de Torreparedones (Castro del Río-Baena. Córdoba). Córdoba.

MORILLO CERDÁN, A. (1999): Lucernas romanas en la región septentrional de la Península Ibérica. Contribución al conocimiento de la implantación romana en Hispania. Monographies Instrumentum 8. Montagnac.

MORILLO CERDÁN, A. (2003): “Las Lucernas”, en L. Berrocal-Rangel y C. Ruiz Triviño (eds.), El depósito alto-imperial del Castrejón de Capote (Higuera la Real, Badajoz). Memorias de Arqueología Extremeña 5: 69-99. Consejería de Cultura, Mérida.

ORTIZ ROMERO, P. (1991): "Excavaciones y sondeos en los recintos tipo torre de La Serena, Badajoz", Extremadura Arqueológica II: 301-317.

ORTIZ ROMERO, P. y RODRÍGUEZ DÍAZ, A. (1998): “Culturas indígenas y romanización en Extremadura: castros, oppida y recintos ciclópeos", en
A. Rodríguez Díaz (coord.), Extremadura protohistórica: paleoambiente, economía y doblamiento: 247-278. Universidad de Extremadura, Cáceres.

PASQUIER, A. (1977): "Pan et les Nymphes à l'antre corycien", Bulletin de correspondance hellénique. Supplément, volume 4, nº1: 365-387.

PÉREZ BALLESTER, J. (1992): "El abrigo de Reinà (Alcalá de Júcar): ensayo sobre un nuevo modelo de lugar de culto en época ibérica", Estudios de arqueología ibérica y romana: homenaje a Enrique Pla Ballester. Serie Trabajos Varios S.I.P. 89: 289-300.

PRADOS TORREIRA, L. (1994): "Los santuarios ibéricos. Apuntes para el desarrollo de una arqueología del culto", TP 51 (1): 127-140.

PRADOS TORREIRA, L. (1996): "Los ritos de paso y su reflejo en la toréutica ibérica" en R. Olmos Romera y A. Santos Velasco (coords.), Iconografía ibérica, iconografia itálica: propuestas de interpretación y lectura: :273-282. Universidad Autónoma de Madrid, Madrid.

QUINTANA FRÍAS, I. y BOIXEREU VILA, E. (2006): "Los recursos mineros como factor de distribución de las estelas decoradas en el Noreste de la provincia de Badajoz", Actas del III Simposio sobre mineraçao e metalurgia historicas no sudoeste europeo: 79-93. Sociedad Española para la Defensa del Patrimonio Geológico y Minero.

RODRÍGUEZ DÍAZ, A. (1993): "Sobre la periferia turdetana y la configuración diversa de la Beturia prerromana: Célticos y Túrdulos en el Guadiana Medio", Spal 2: 243-268. http://dx.doi.org/10.12795/ spal.1993.i2.10

RODRÍGUEZ DÍAZ, A. (1995): "Extremadura Prerromana”, Extremadura arqueológica IV: 91-122.

RODRÍGUEZ DÍAZ, A. y ORTIZ ROMERO, P. (2003):

"Defensa y territorio en la Beturia: castros, oppida y recintos ciclópeos", en A. Morillo, F. Cadiou y D. Hourcade (coords.), Defensa y territorio en Hispania de los Escipiones a Augusto: espacios urbanos y rurales, municipales y provinciales: 219-252. Universidad de León-Casa de Velásquez, León.

RODRÍGUEZ MARTÍN, G. (1996): Materiales de un alfar emeritense: paredes, lucernas, sigillatas y terracotas. Cuadernos emeritenses 11. Mérida.

RODRÍGUEZ MARTÍN, G. (2002): Lucernas romanas del Museo Nacional de Arte Romano (Mérida). Monografías emeritenses 7. Ministerio de Educación, Cultura y Deporte, Subdirección General de Publicaciones. Madrid.

RODRÍGUEZ MARTÍN, G. (2005): “Lucernas”, Antigüedades romanas II. Publicaciones del Gabinete de Antigüedades de la Real Academia de la Historia, Madrid. 
RUANO RUIZ, E. (1988): “El Cerro de los Santos (Montealegre del Castillo, Albacete): una nueva interpretación del santuario", CuPAUAM 15: 262-265.

RUANO RUIZ, E. y SAN NICOLÁS DEL TORO, M. (1990): "Exvotos ibéricos procedentes de 'La Encarnación' (Caravaca, Murcia)", Verdolay 2: 101-107.

RUEDA GALÁN, C.; GUTIÉRREZ, L.M ${ }^{\mathrm{a}}$. y BELLÓN, J.P. (2008): “Aportación desde los procesos territoriales a las lecturas iconográficas de los santuarios del Alto Guadalquivir", Anales de Arqueología Cordobesa 19: 23-48.

RUIZ BREMÓN, M. (1988): “Aproximación al estudio del santuario ibérico de La Luz.", AEspA 61: 230-244.

SEGARRA CRESPO, D. (1997): "La alteridad ritualizada en la ofrenda", Habis 28: 275-298.

SERRANO RAMOS, E. (1999): “Producciones hispánicas precoces”, en M. Roca y $\mathrm{M}^{\mathrm{a}}$.I. Fernández García (coords), Terra sigillata hispánica. Centros de fabricación y producciones alto-imperiales: 231233. Universidad de Jaén-Universidad de Málaga.

TARRADELL, M. (1973): "Cuevas sagradas o cuevas santuarios. Un aspecto poco valorado de la religión ibérica", Memoria del Instituto de Arqueología y Prehistoria: 25-40. Universidad de Barcelona, Barcelona.

VAQUERIZO GIL, D. (1985): "La cueva de la Murcielaguina en Priego de Córdoba, posible cueva-santuario ibérica", Lucentum. Anales de la Universidad de Alicante 4: 115-124.

VAQUERIZO GIL, D. (1997): “Testimonios de religiosidad ibérica en territorio de la actual provincia de Córdoba", Quaderns de Prehistòria i Arqueologia de Castelló 18: 297-328.

VEGAS, M. (1973): Cerámica común romana del Mediterráneo occidental. Instituto de Arqueología y Prehistoria, Universidad de Barcelona. Barcelona.

WALID, S. y NUÑO, R. (2005): "Aplicaciones arqueogeográficas al estudio de las sociedades del período orientalizante. ¿Quién construyó Cancho Roano?”, en S. Celestino Pérez y J. Jiménez Ávila (eds.), El Periodo Orientalizante. Actas del III Simposio Internacional de Arqueología de Mérida: Protohistoria del Mediterráneo Occidental: 977-984. CSIC, Mérida.

ZARZALEJOS, M. (1995): Arqueología de la región sisaponense. Aproximación a la evolución histórica del extremo $S W$ de la provincia de Ciudad Real (fines del siglo VIII a.C. al II d.C.). Madrid.

ZARZALEJOS, M. (2003): "Las producciones de TSH precoz. Las sigillatas de imitación de tipo Peñaflor", en L. Berrocal-Rangel y C. Ruiz Triviño (eds.), El depósito alto-imperial del Castrejón de Capote (Higuera la Real, Badajoz). Memorias de Arqueología Extremeña 5: 133-135. Consejería de Cultura, Mérida. 